\title{
Ecology and Geography of Human Monkeypox Case Occurrences Across Africa
}

Christine Ellis DVM Kansas State University College of Veterinary Medicine Manhattan, KS 
- Monkeypox Ecological Niche Modeling

- My Project 


\section{Introduction to Monkeypox}




\section{Monkeypox - Virus}

- Orthopoxvirus, Poxviridae, Chordopoxvirinae

$\square$ cowpox, vaccinia, variola

- Central genome tightly conserved

$\square$ Key functions:

- transcription, virus assembly

- Genes at termini are more variable

$\square$ Associated with virus-host interactions 


\section{Monkeypox - Virus}

- 2 geographically distinct clades

$\square$ Congo Basin clade

$\square$ West African clade

- $99 \%$ identical

$\square$ Diversity is located in the terminal regions

- West African clade

$\square$ Less virulent

$\square$ Less transmissible

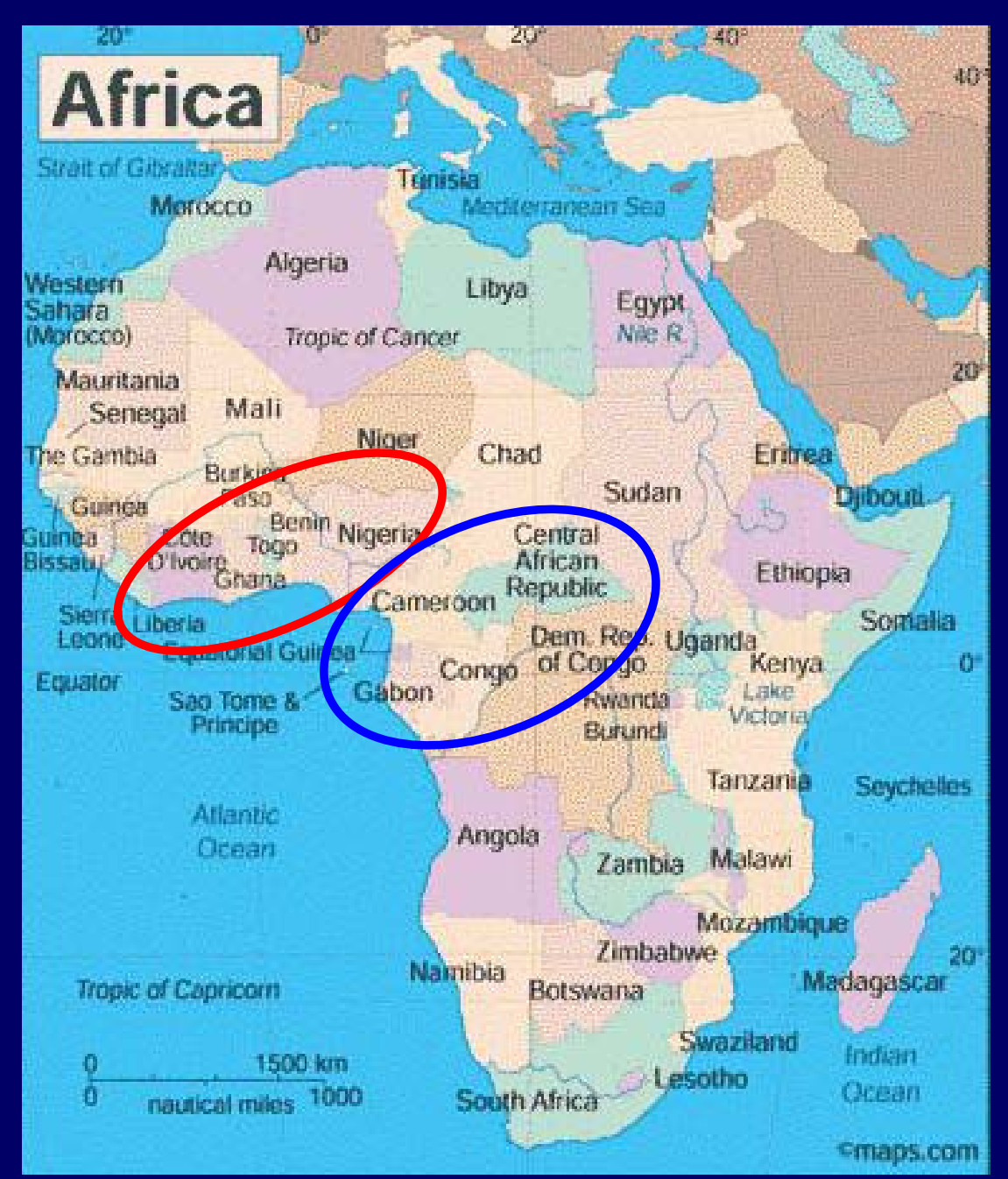

www.rst.gsfc.nasa.gov/Sect6/Sect6 


\section{Monkeypox - Human Disease}

口 "Emerged" in 1970-1971

$\square$ After successful eradication of smallpox

- West and Central Africa

$\square$ rural, tropical rainforest areas

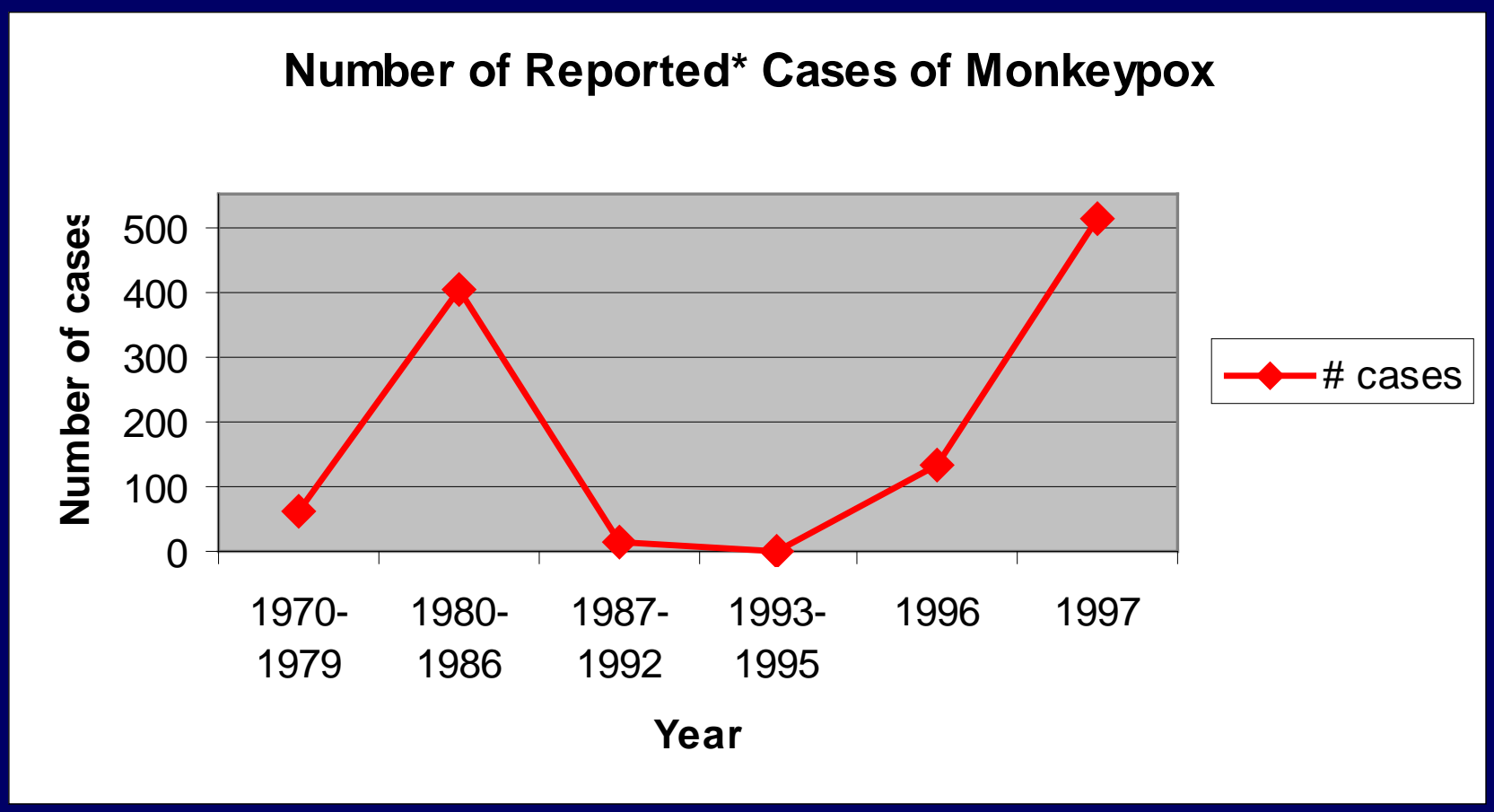




\section{Monkeypox - Human Disease}

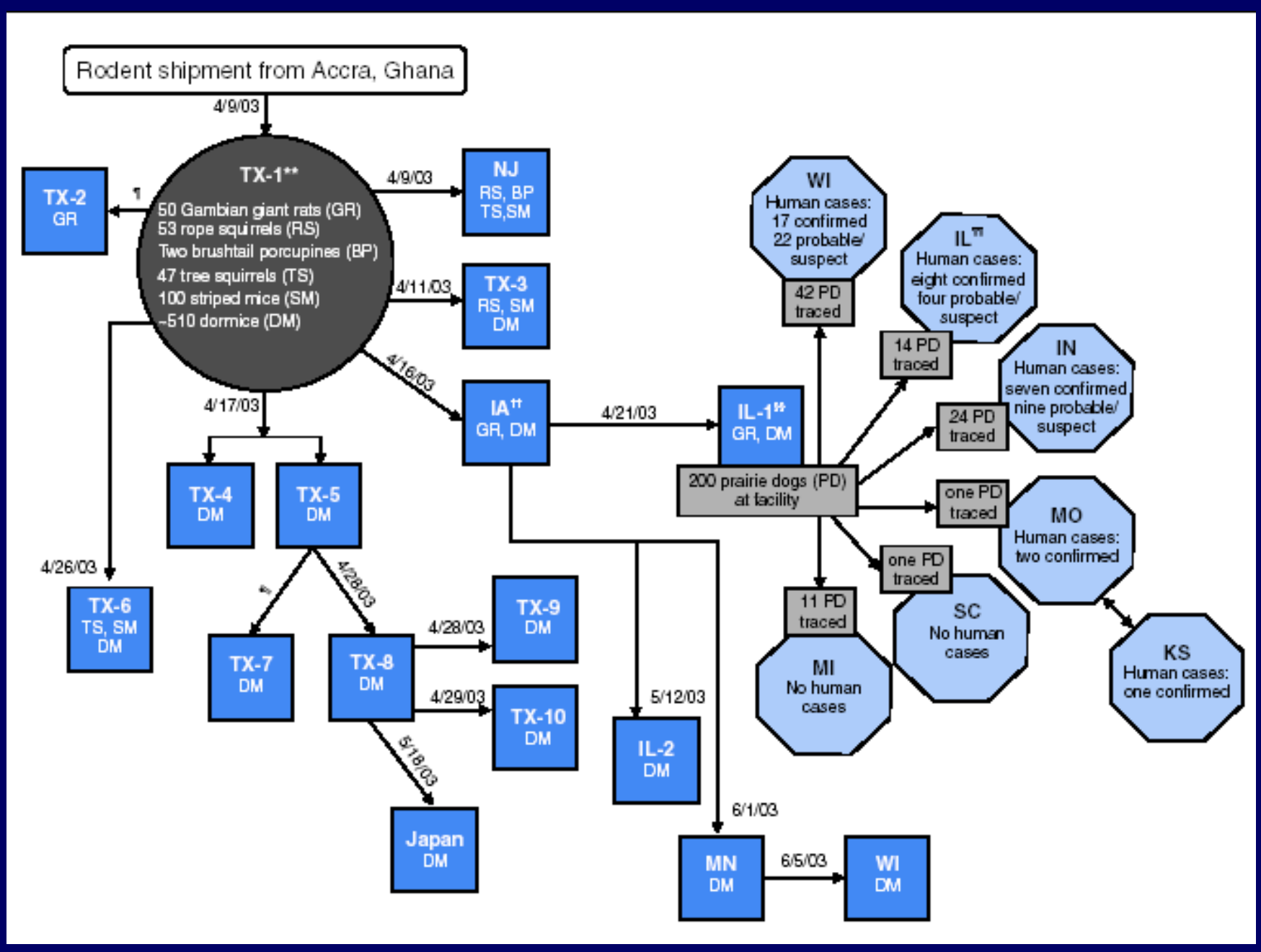




\section{Monkeypox - Human Disease}

Source of virus

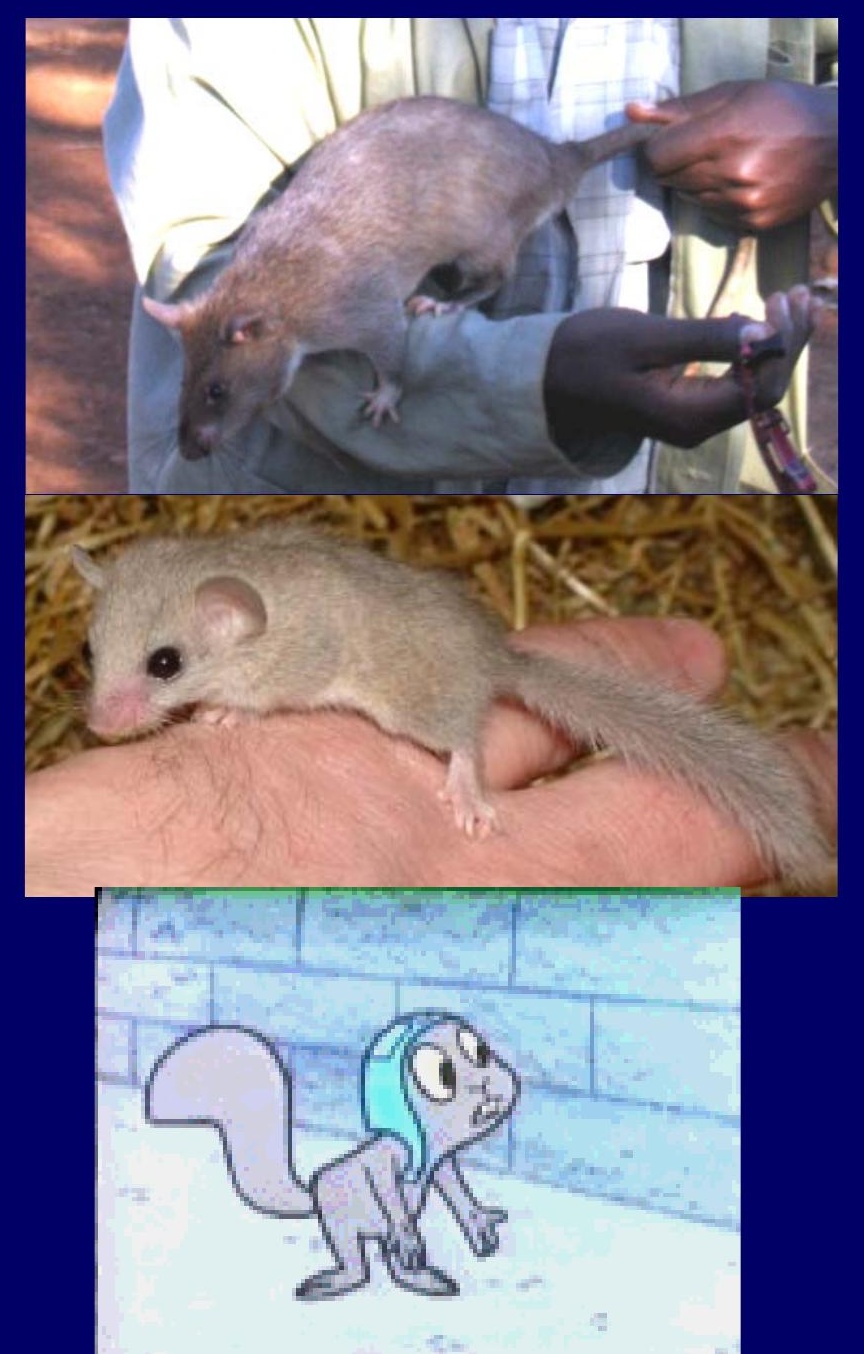

Source of human infection

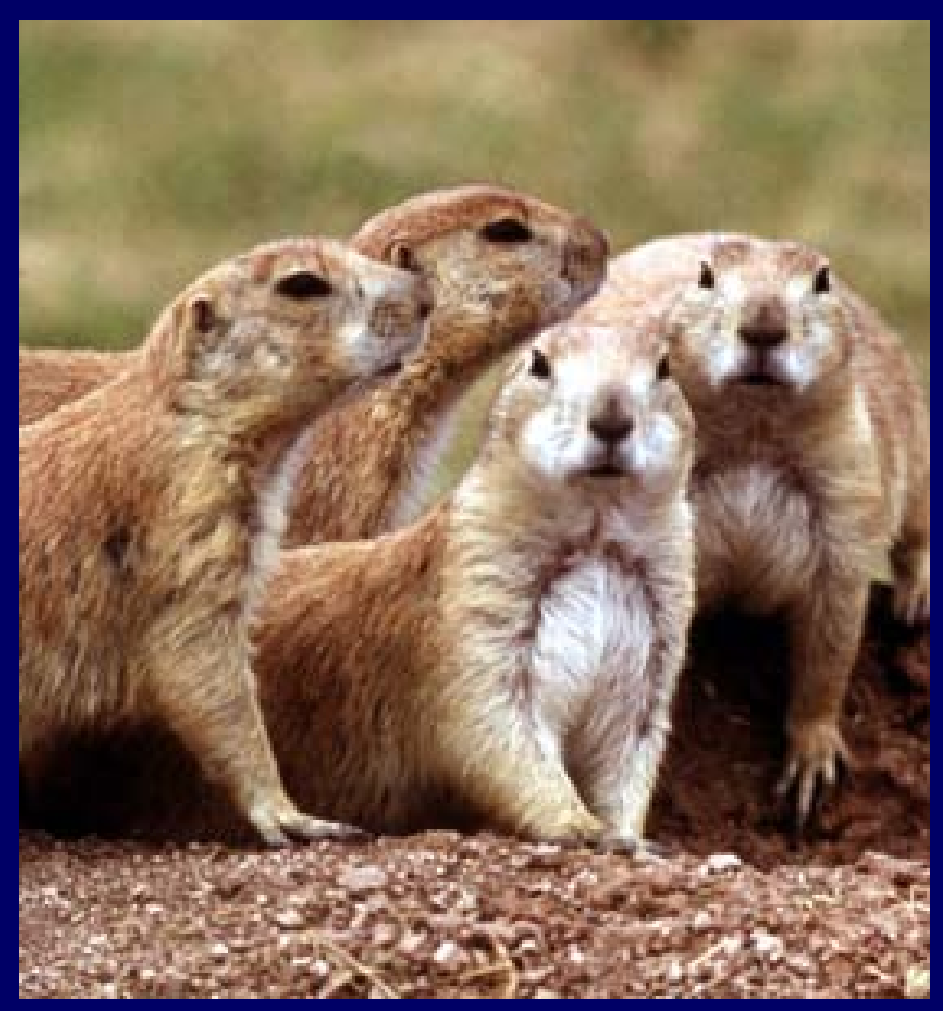

www.nps.gov

photos.igougo.com www.pets-classifieds.co.uk www.everwonder.com/david/bullwinkle 


\section{Monkeypox - Clinical Presentation}

- 10-14 day incubation

- 1-3 day prodrome

$\square$ Fever, malaise, lymphadenopathy, URT illness

- 2-4 weeks: febrile rash illness:

$\square$ Begins on the trunk, spreads centrifugally

$\square$ Macular, papular, vesicular, pustular stages

- Complications

$\square$ DIC, ocular lesions, CNS disease, multi-organ failure

$\square$ Death

- Case fatality $10 \%$ (range: $1.7-17 \%$ )

$\square$ Children $<10$ years 

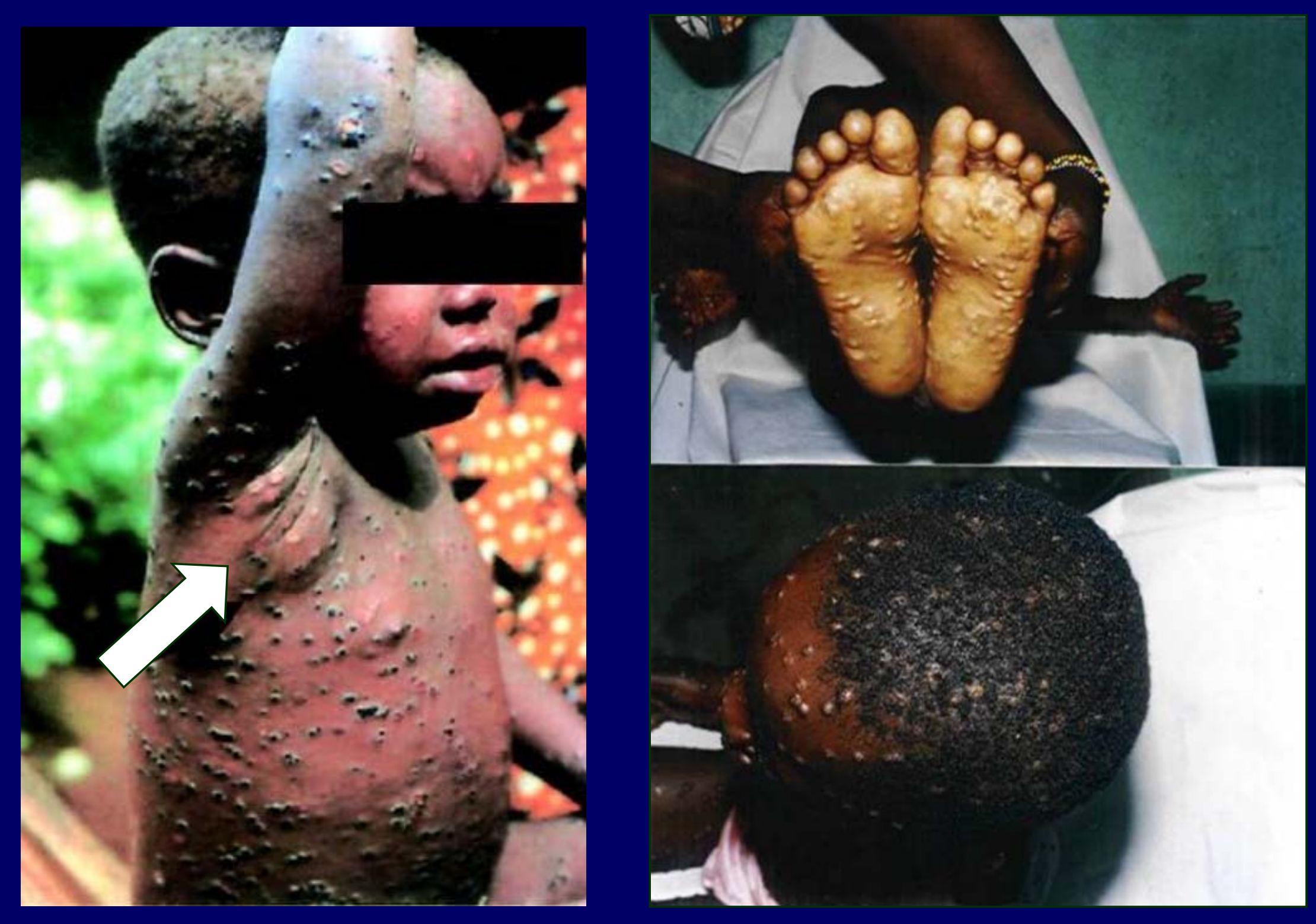

www.ci.vbi.vt.edu/pathinfo/pathogens/Monkeypox_virus_Info.shtml 


\section{Monkeypox - Epidemiology}

- Endemic to West and Central Africa

$\square$ Tropical rainforest regions

- Epidemiologic range not definitively identified

- Human cases occur sporadically in clusters

$\square 80 \%$ in the DRC (Congo Basin) 


\section{Monkeypox - Epidemiology}

- Transmission:

$\square$ Direct contact

- infected animals

$\square$ Human-to-Human ( 9\%)

- direct contact

- respiratory aerosol

- body fluids

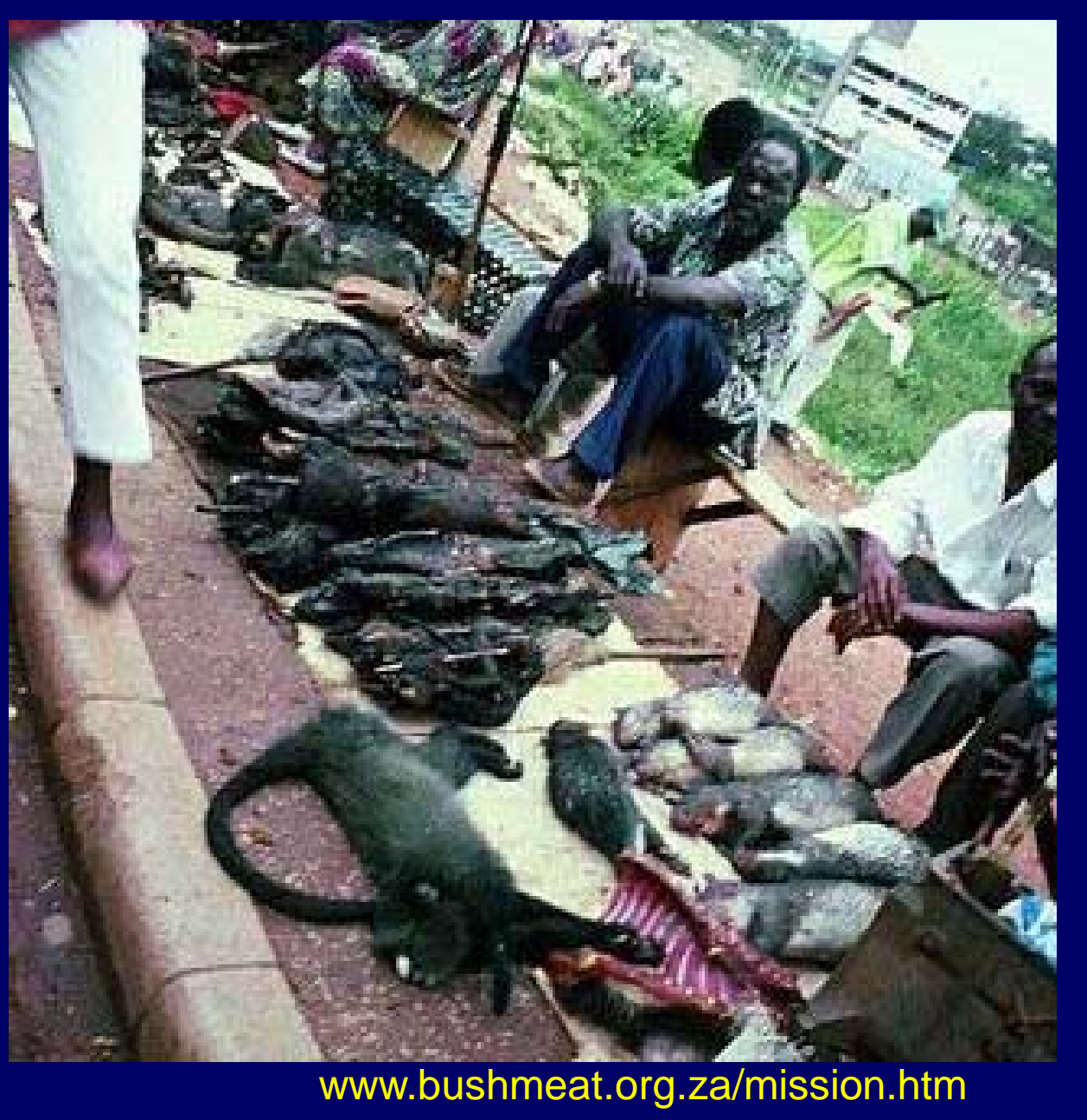




\section{Monkeypox - Epidemiology}

- Zoonotic Reservoir Host(s) - unknown

- WHO and CDC ecological surveys

$\square 13$ rodents

$\square 10$ primates

$\square 3$ other mammals

$\square 2$ birds

- Virus isolated twice

$\square 1985$

$\square 2003$
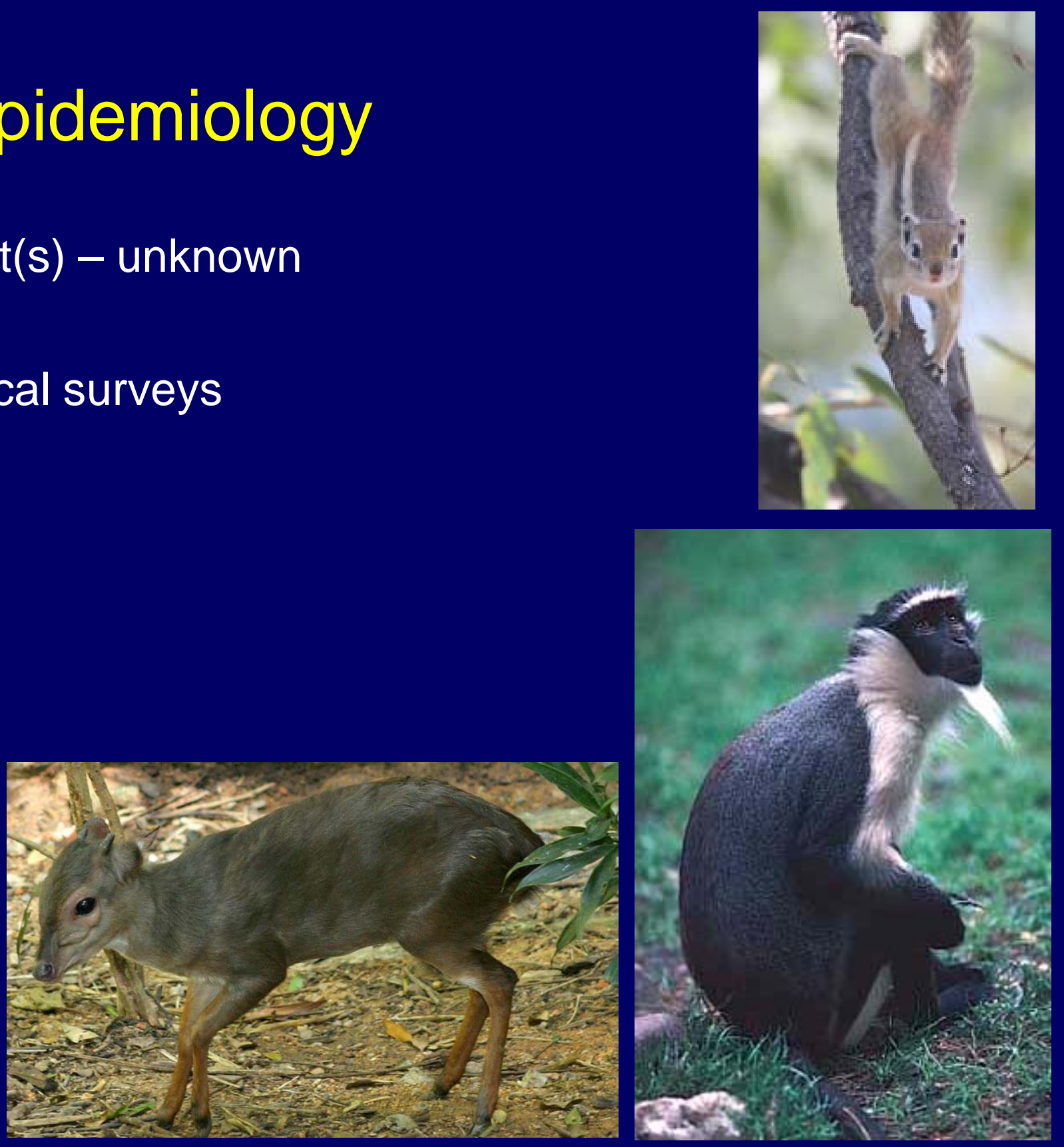


\section{Monkeypox - Why Is It Important?}

- WHO: "the most significant orthopoxvirus infection of man with regards to surveillance and research"

- Possible bioterrorism agent

- Clinically similar to smallpox

- Preventable but not eradicable 


\section{Monkeypox - Why Is It Important?}

- Broad host range:

$\square$ Large number of potential hosts

$\square$ Endemic and novel landscapes

- Increasing incidence?

$\square$ Encroachment

$\square$ Ecosystem degradation

$\square$ Susceptible individuals

$\square$ Concomitant disease

$\square$ Socioeconomic factors

$\square$ Better surveillance?

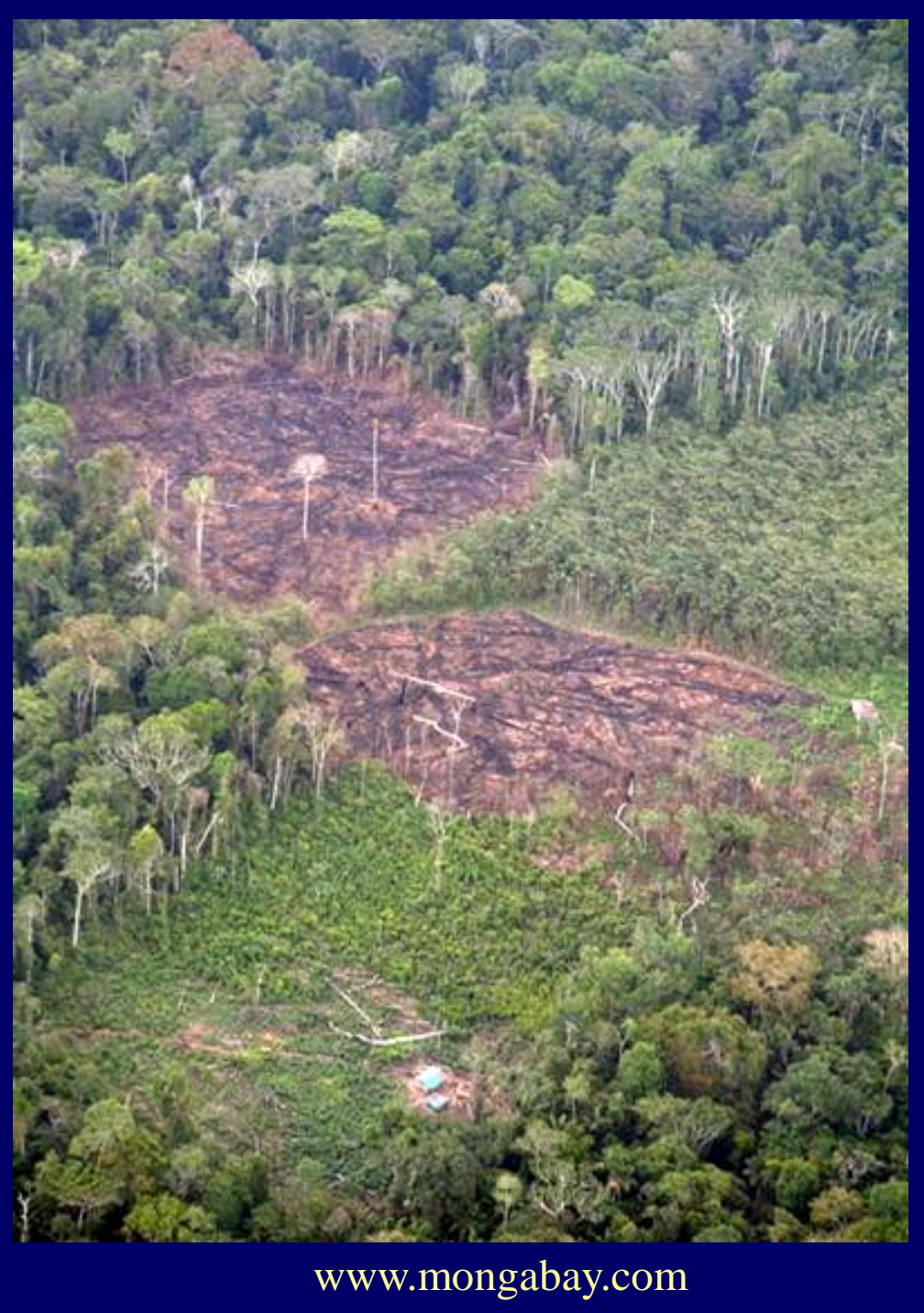




\section{Introduction to Niche Modeling}




\section{Ecological Niche Modeling}

- Ecological niche

$\square$ Set of environmental conditions capable of maintaining a population without immigration

- Ecological niche model

$\square$ A set of environmental conditions classified as suitable (versus unsuitable) for the species, based on

- localities of known occurrence

- environmental variables

$\square$ Integrated into a GIS system

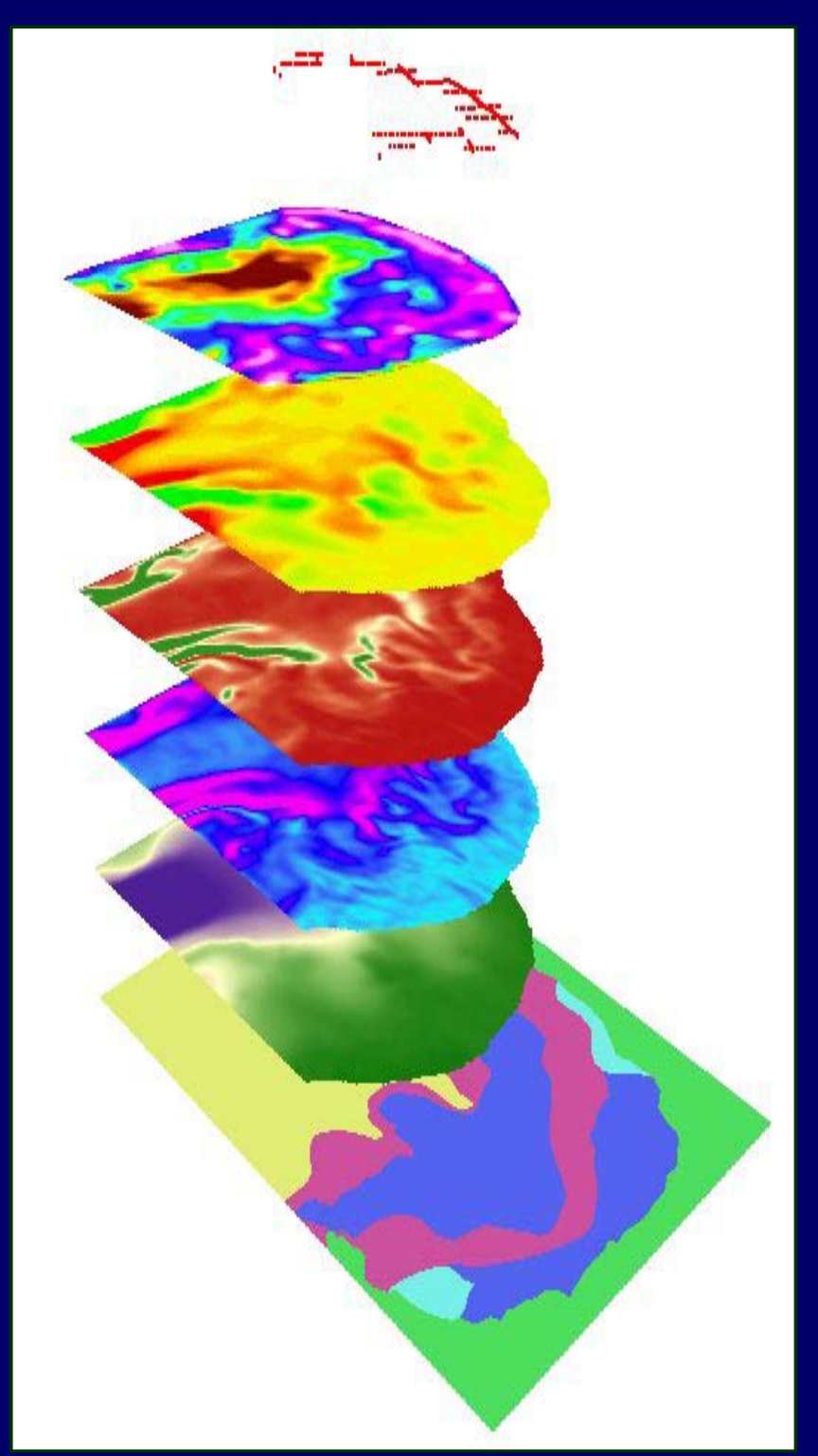




\section{Ecological Niche Modeling - Uses}

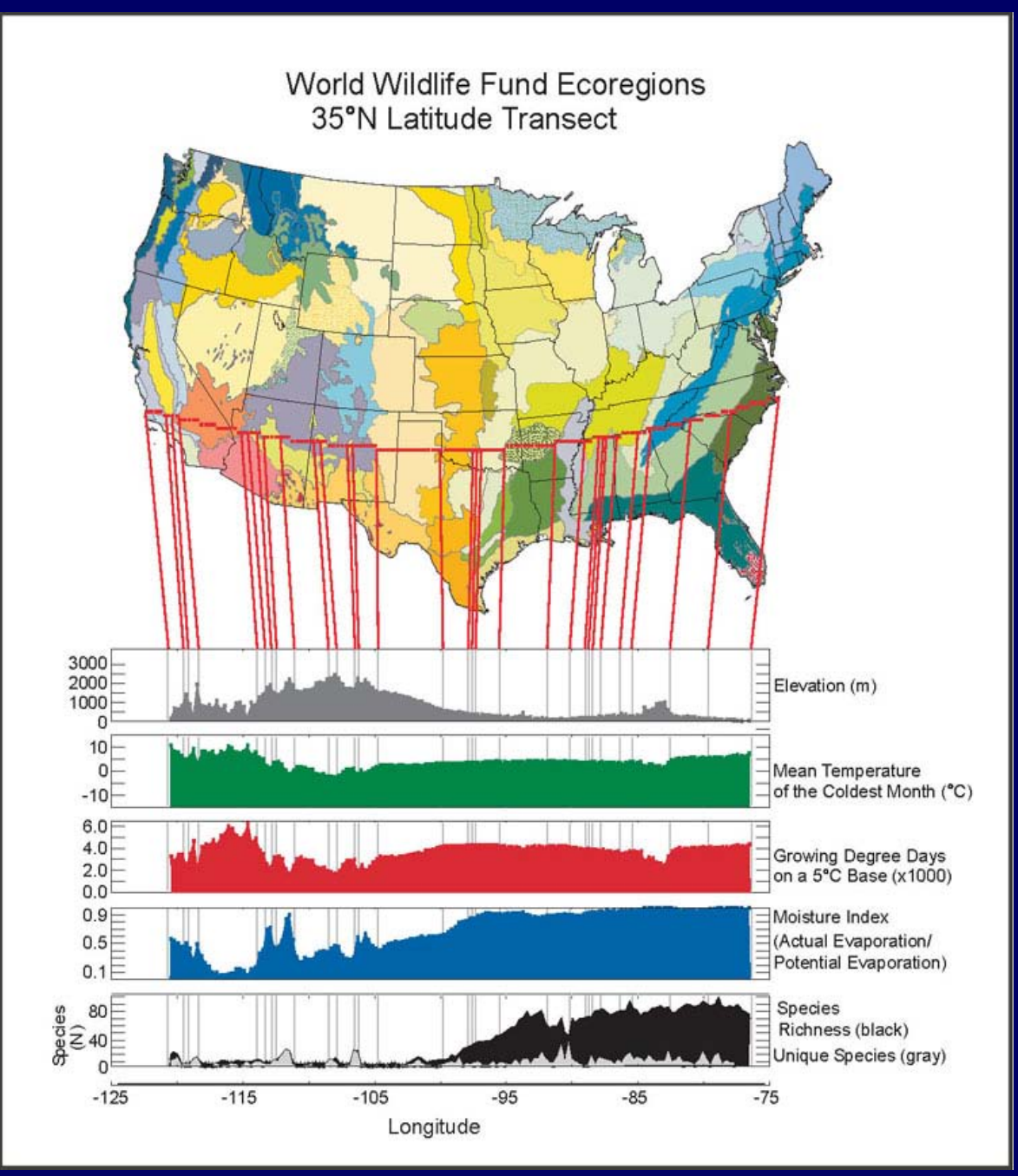

- Biogeographic research

- Conservation biology

- Ecology

- Paleoecology

- Wildlife conservation

- Spatial epidemiology 


\section{Ecological Niche Modeling}

\section{Spatial Epidemiology}

The geographic distribution of disease is an epidemiological event

occurring at the convergence of each participating population's ecological niche

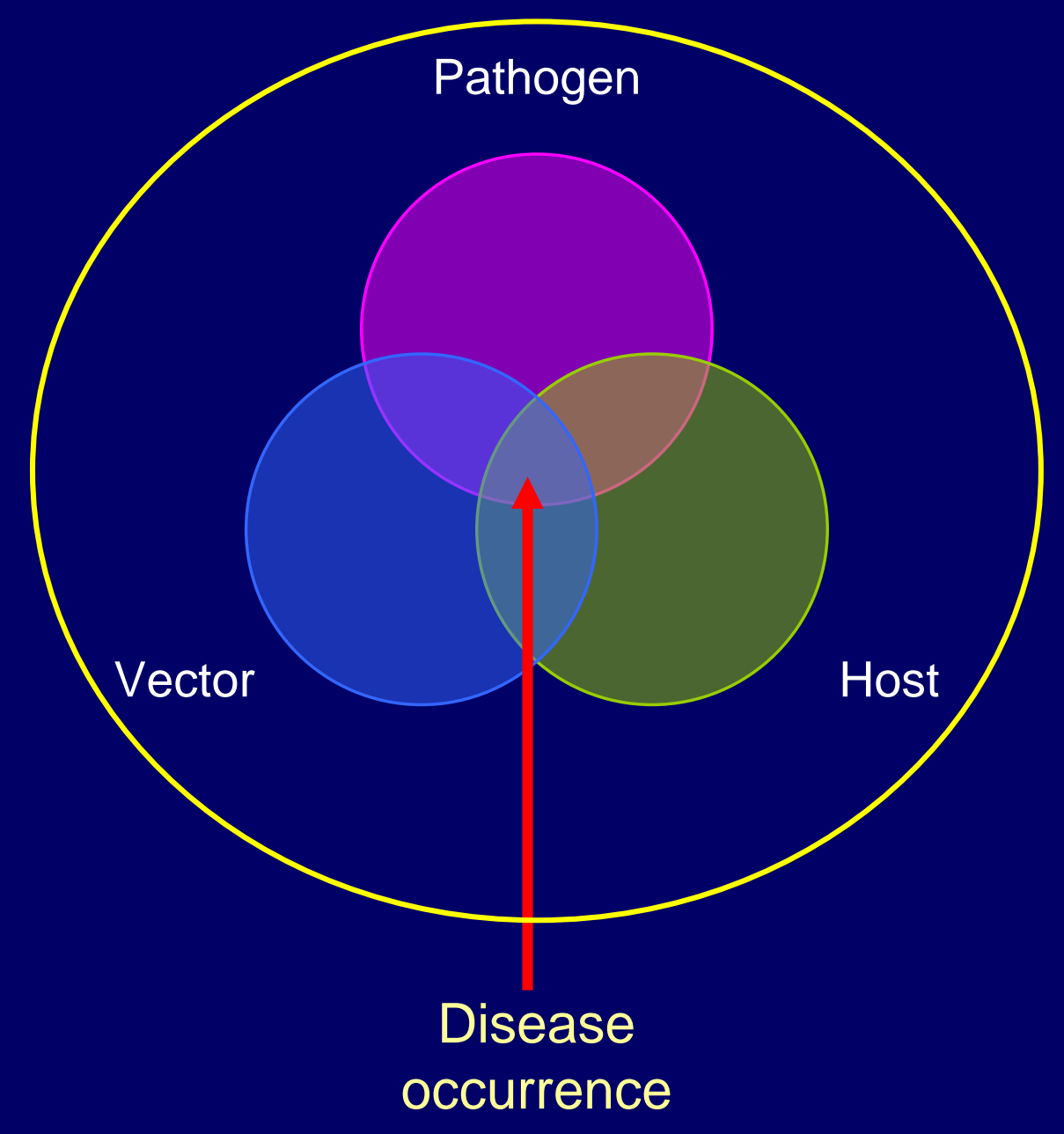




\section{ENM Example: \\ Invasion of the USA by Aedes albopictus}

- Invader

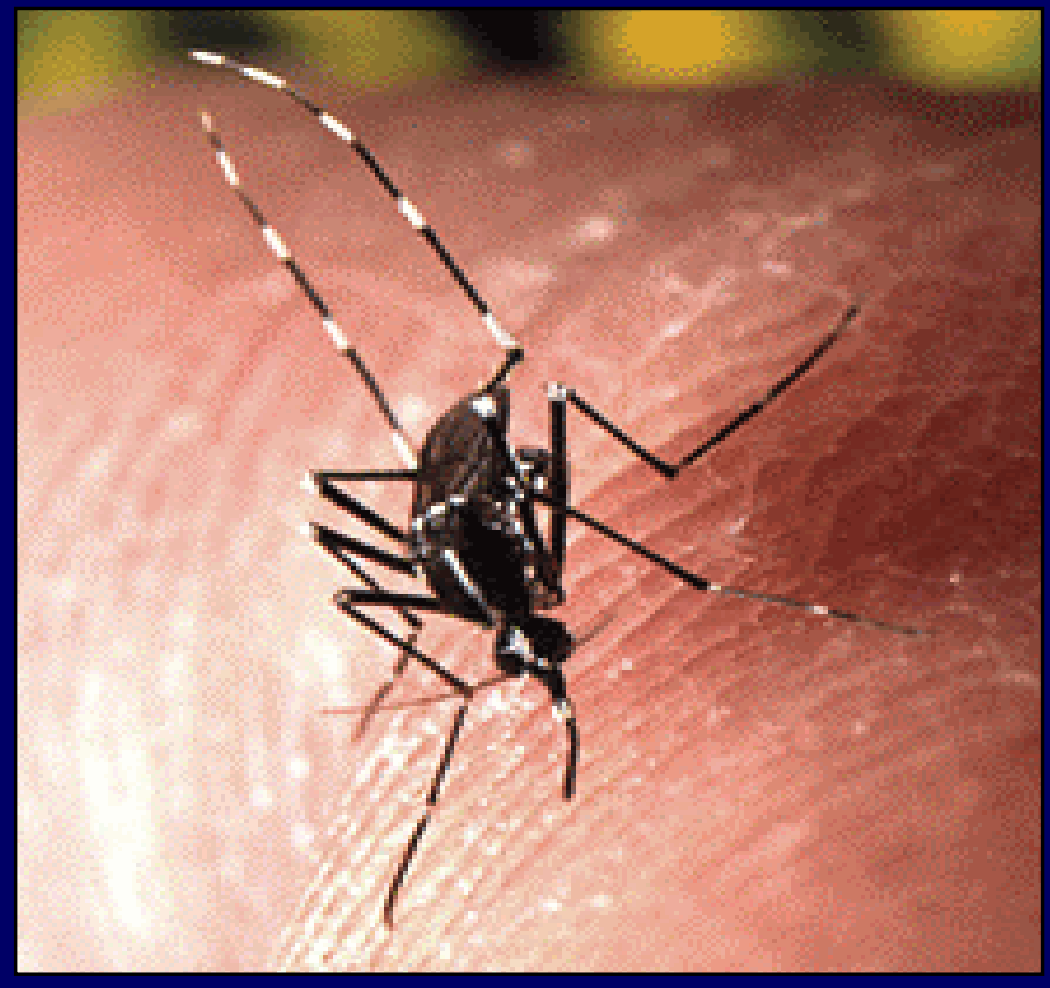

Mark Q. Benedict et al

Vector-Borne and Zoonotic Diseases. March 1, 2007, 7(1): 76-85. doi:10.1089/vbz.2006.0562. $\square$ Fastest spreading mosquito in the world

- Aggressive

$\square$ Daytime biter

- Transmits

$\square$ Dengue, WNV

$\square$ Encephalitis viruses

- (LCE, SLE, EEE)

$\square$ Ross River fever

$\square$ Rift Valley fever 


\section{Aedes albopictus: Native Range}

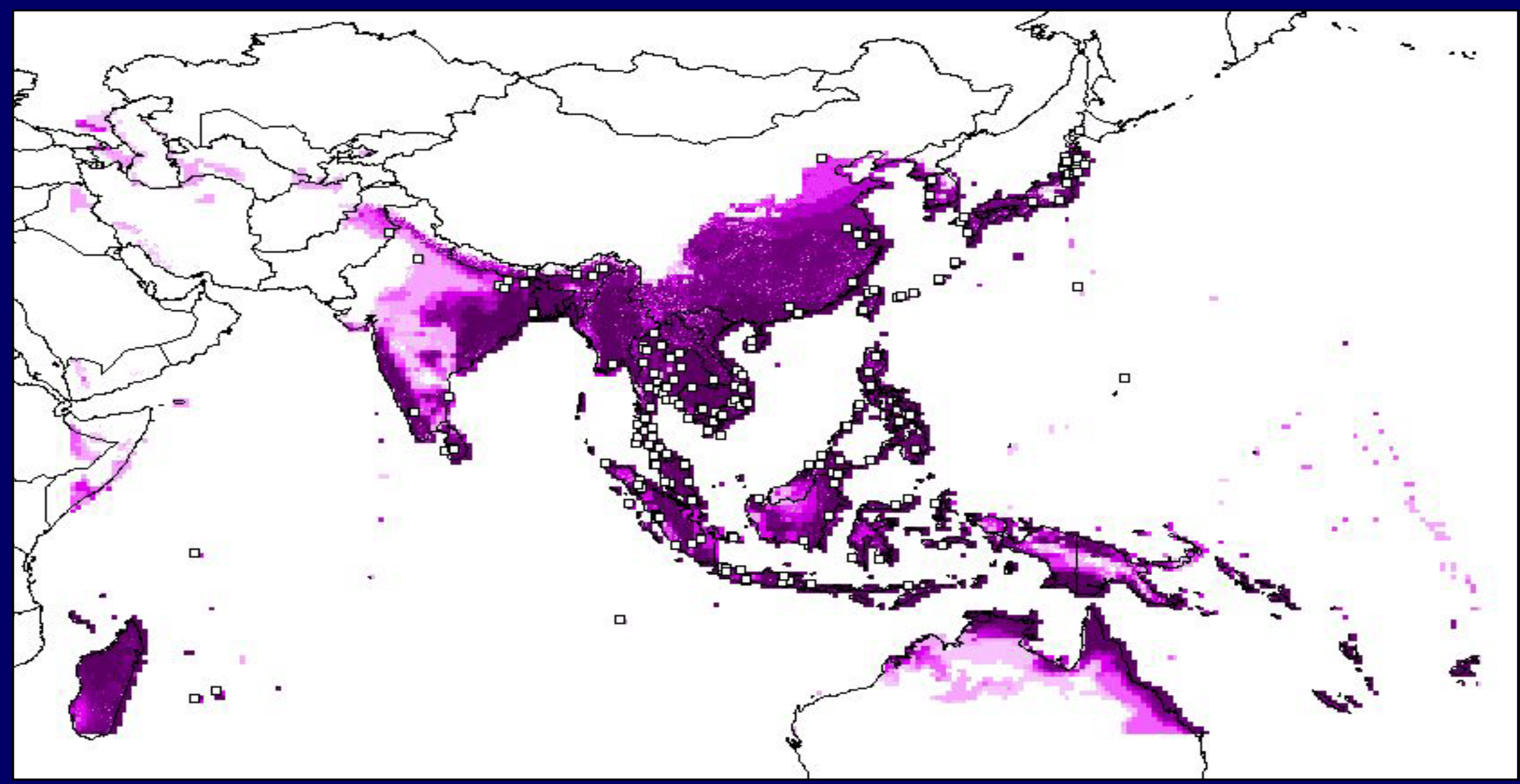

Present predicted distribution, native range in Asia Mark Q. Benedict et al 


\section{Aedes albopictus: USA invasion}

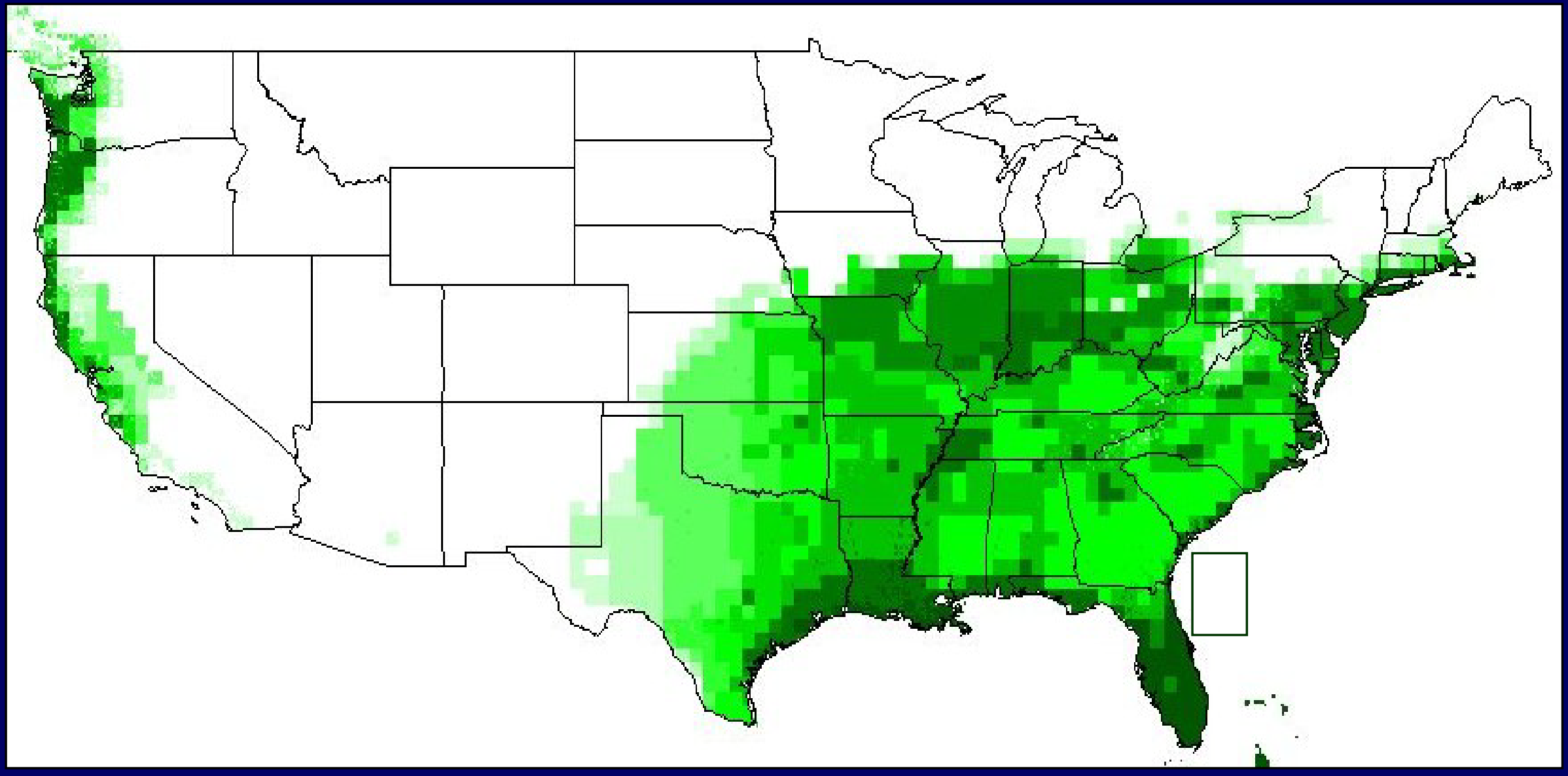

Projected Asian niche into USA to create an invasion risk-map.

Mark Q. Benedict et al 


\section{Aedes albopictus: USA invasion}

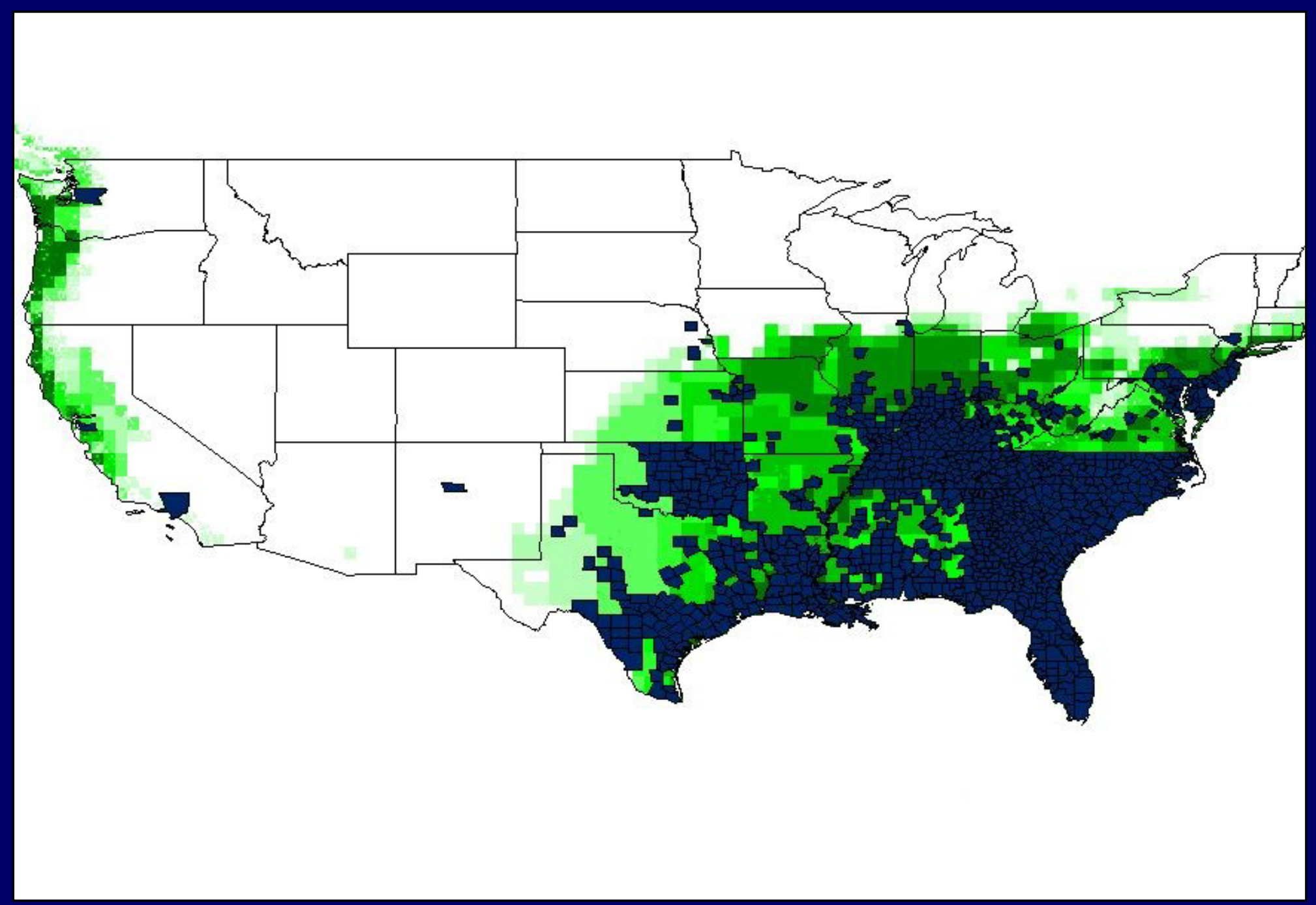

Mark Q. Benedict et al 
My Project 


\section{Ecology and Geography of Human Monkeypox Case Occurrences Across Africa}

Goal:

1) Identify ecological factors relevant to the geographic distribution of monkeypox in Africa

2) Use this knowledge to understand better the geography of monkeypox across Africa

3) Perform a comparative assessment of ENM methodology 


\section{Occurrence Data}

- Occurrence Data:

$\square \mathrm{CDC}$ and WHO

- outbreak investigation and surveillance data

- Case Definition:

$\square$ Laboratory confirmed

- Published reported case

- Non-redundant unpublished case 


\section{Occurrence Data}

- Georeferencing Case Occurrence

$\square$ Country

$\square$ Region

$\square$ District / Zone

$\square$ Municipality

$\square$ Specific locality

Democratic Republic of the Congo

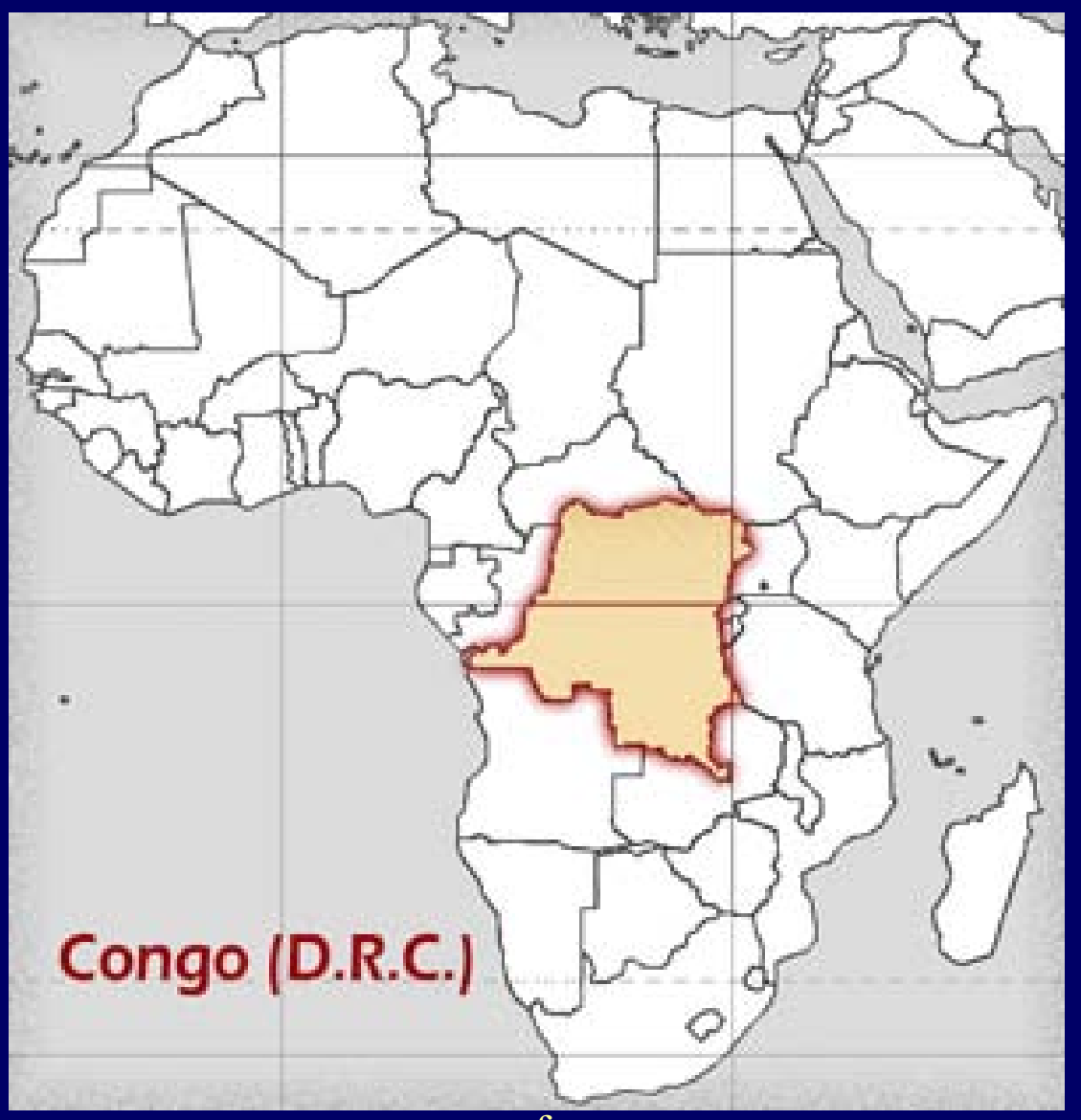




\section{Occurrence Data}

\section{Democratic Republic of the Congo -- Equateur}

- Georeferencing Case Occurrence

$\square$ Country

$\square$ Region

$\square$ District / Zone

$\square$ Municipality

$\square$ Specific locality

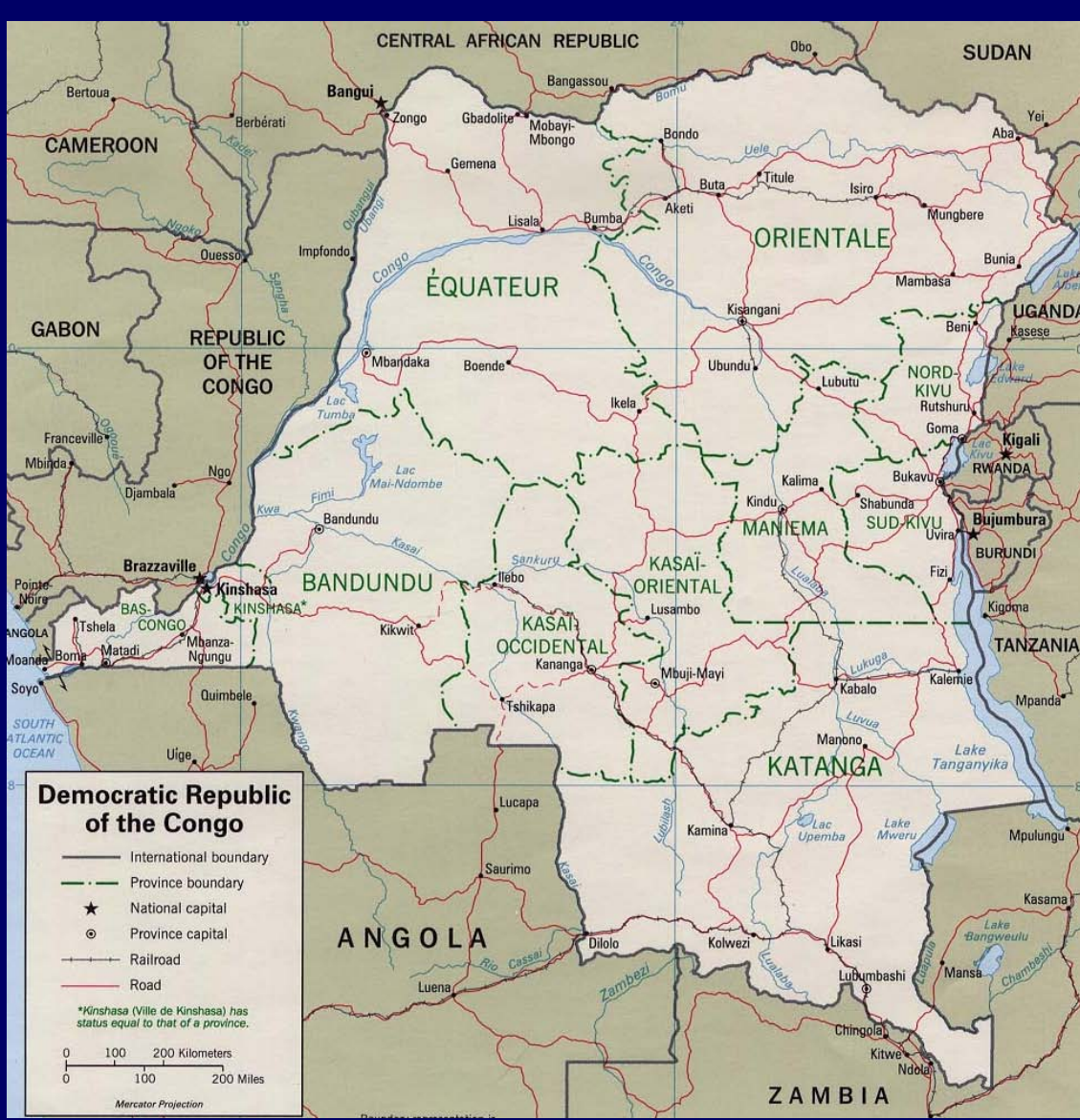

www.lib.utexas.edu/maps/zaire 


\section{Occurrence Data}

\section{Democratic Republic of the Congo - Equateur - Bumba}

- Georeferencing Case Occurrence

$\square$ Country

$\square$ Region

$\square$ District / Zone

$\square$ Municipality

$\square$ Specific locality

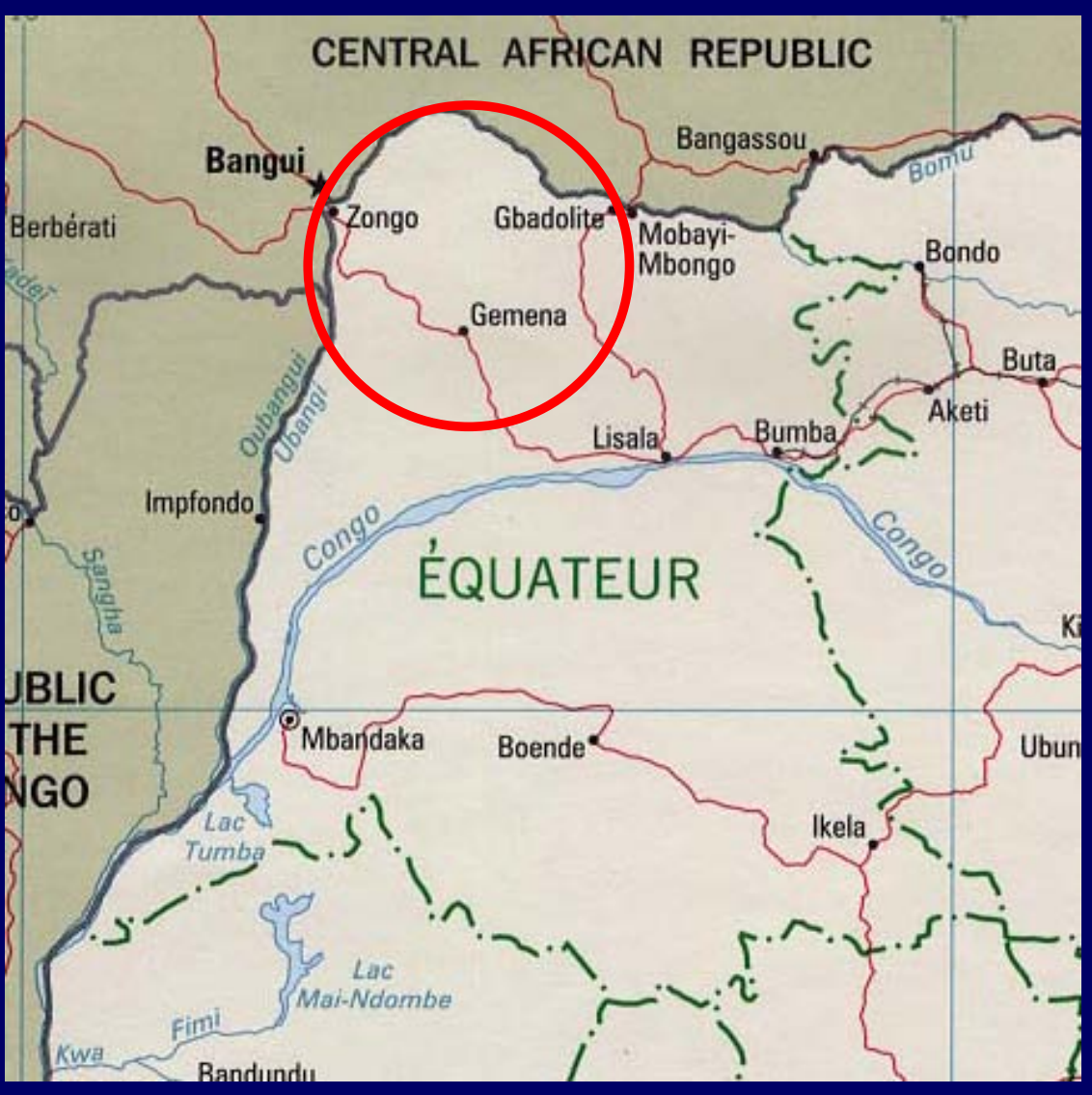

www.lib.utexas. edu/maps/zaire 


\section{Occurrence Data}

Democratic Republic of the Congo - Equateur - Bumba - Gemena

- Georeferencing Case Occurrence

$\square$ Country

$\square$ Region

$\square$ District / Zone

$\square$ Municipality

$\square$ Specific locality

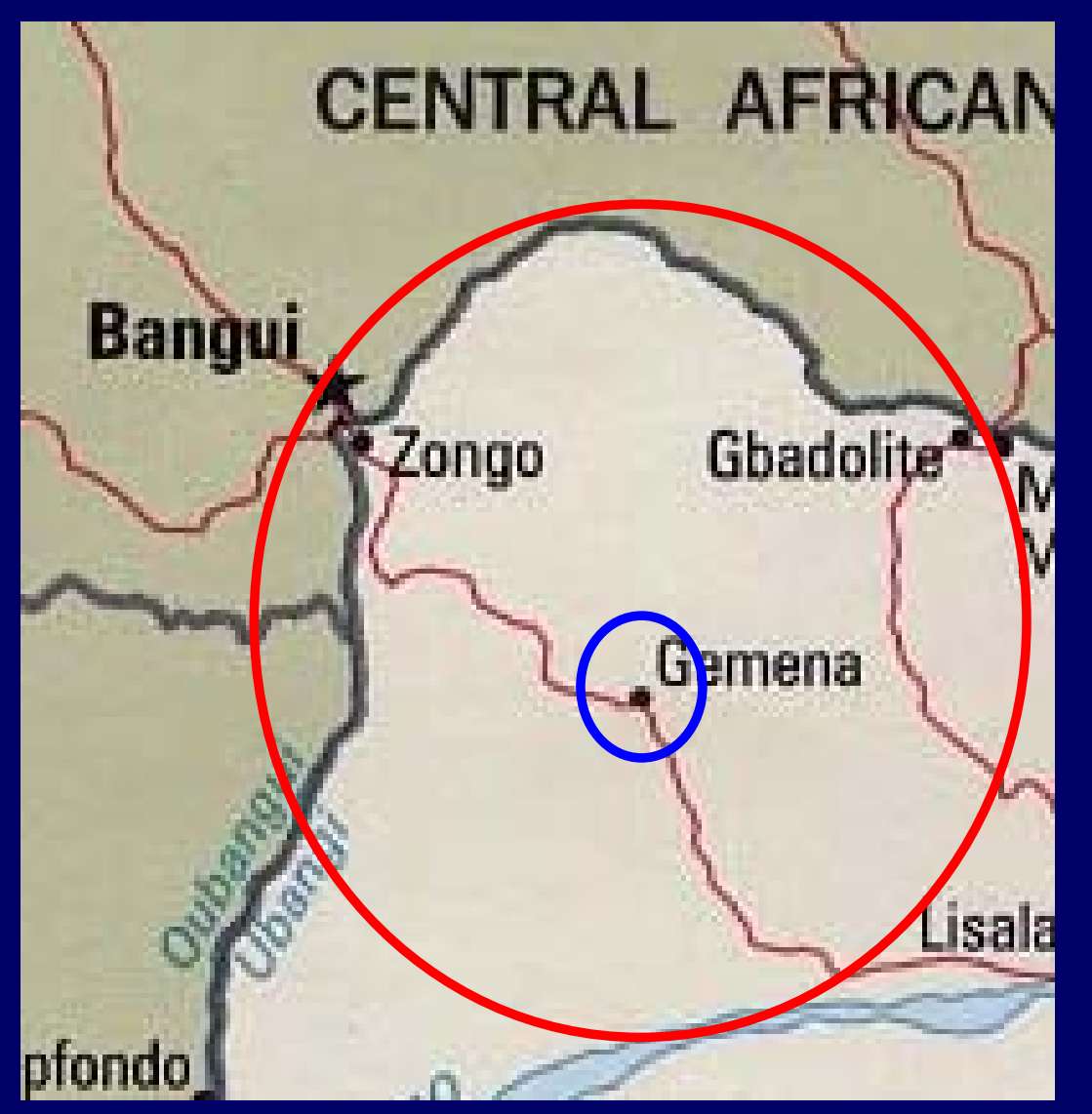

www.lib.utexas.edu/maps/zaire 


\section{Occurrence Data}

Democratic Republic of the Congo - Equateur - Bumba - Gemena - Ebata

- Georeferencing Case Occurrence

$\square$ Country

$\square$ Region

$\square$ District / Zone

$\square$ Municipality

$\square$ Specific locality

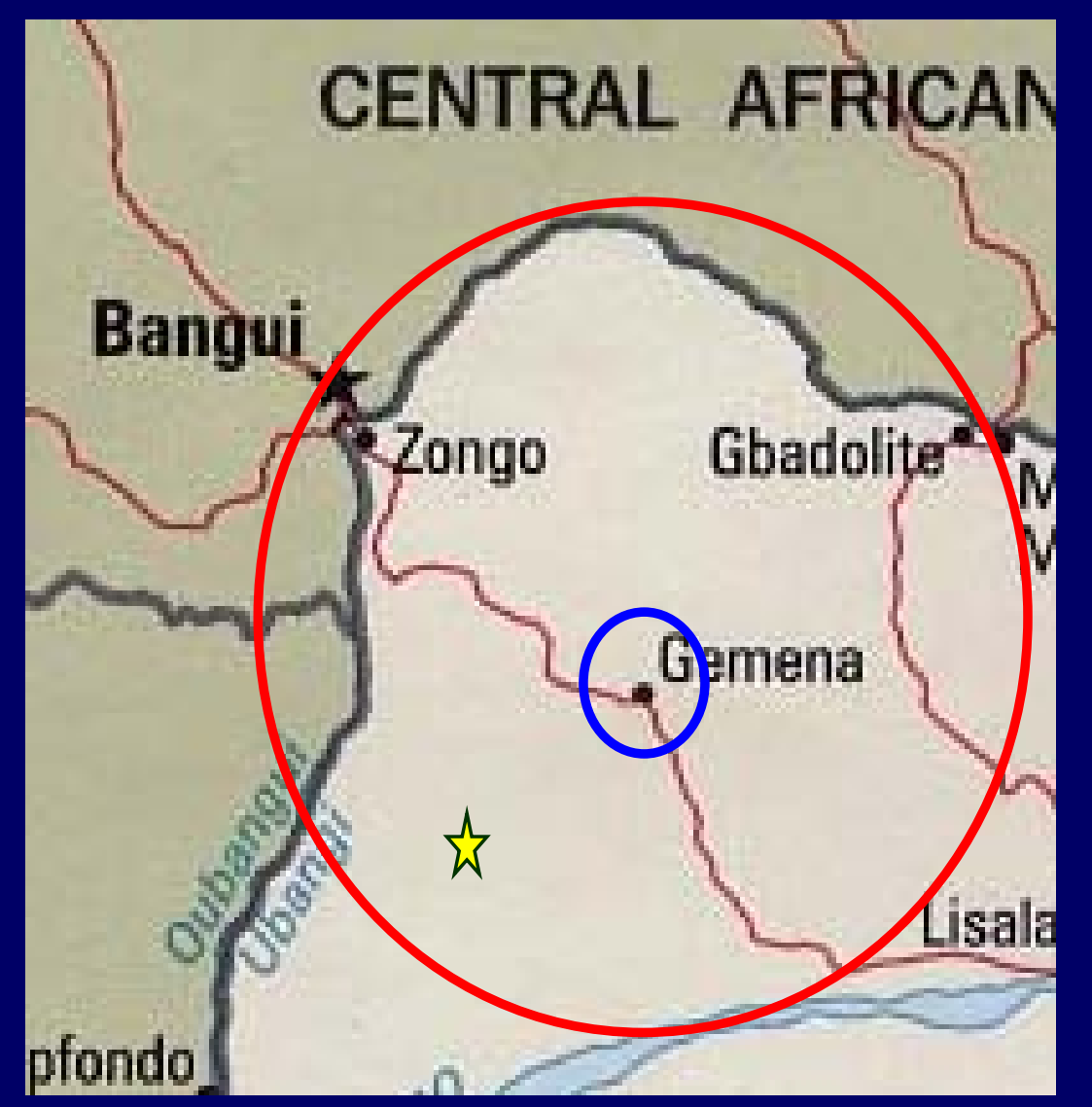

www.lib.utexas.edu/maps/zaire 


\section{Occurrence Data}

- Started with: 404 cases

- Georeferenced: 216 localities

n But, you can't just georeference the occurrence and call it good...

Must account for ..... 


\section{Occurrence Data}

- Error....

Prairie dog town \#2

Sheep dip

Highway marker \#82

- Spatial uncertainty

$\square$ Extent of named places

$\square$ Imprecise locality descriptions

$\square$ Incomplete locality descriptions

$\square$ Datum error

- $10 \mathrm{~cm}-1000$ meters

North side of Rio Grande

Near sand dunes

A few miles east of Maxwell

Next to Land Rover

Bridge east of lodge

North side of Elko

3 miles from Greeley 


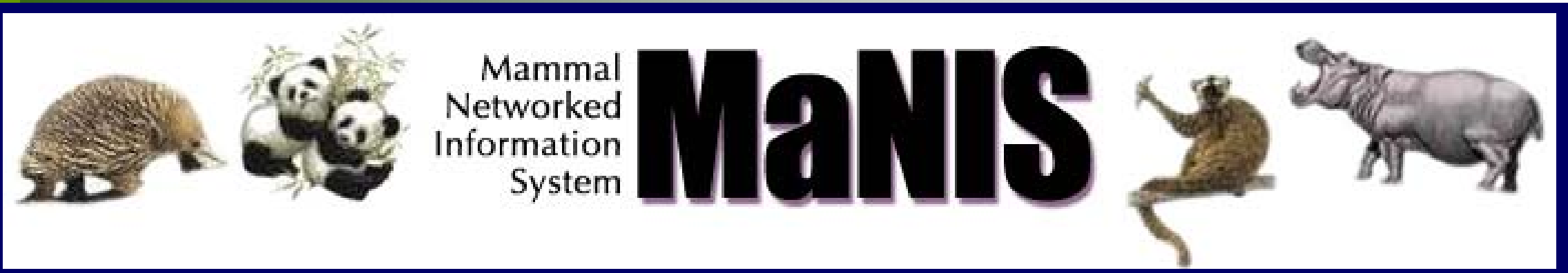

www.manisnet.org

"'georeferencing" or "geocoding," can be rather complicated."

- Georeferencing Manual

$\square$ Contains information about assigning

- Geographic coordinates to locality descriptions

- Extent to those coordinates

- Georeferencing Calculator

- Corrected GPS coordinates

- Assigns an error extent

- Result: greater spatial precision 


\section{Occurrence Data}

Point-radius method:

A locality is a geographic point surrounded by an error extent Summarizes effects of error-related factors

All MPX occurrences were assigned an error radius

Restricted analysis to sites with a precision $=10 \mathrm{~km}^{2}$

139 occurrences for final analysis

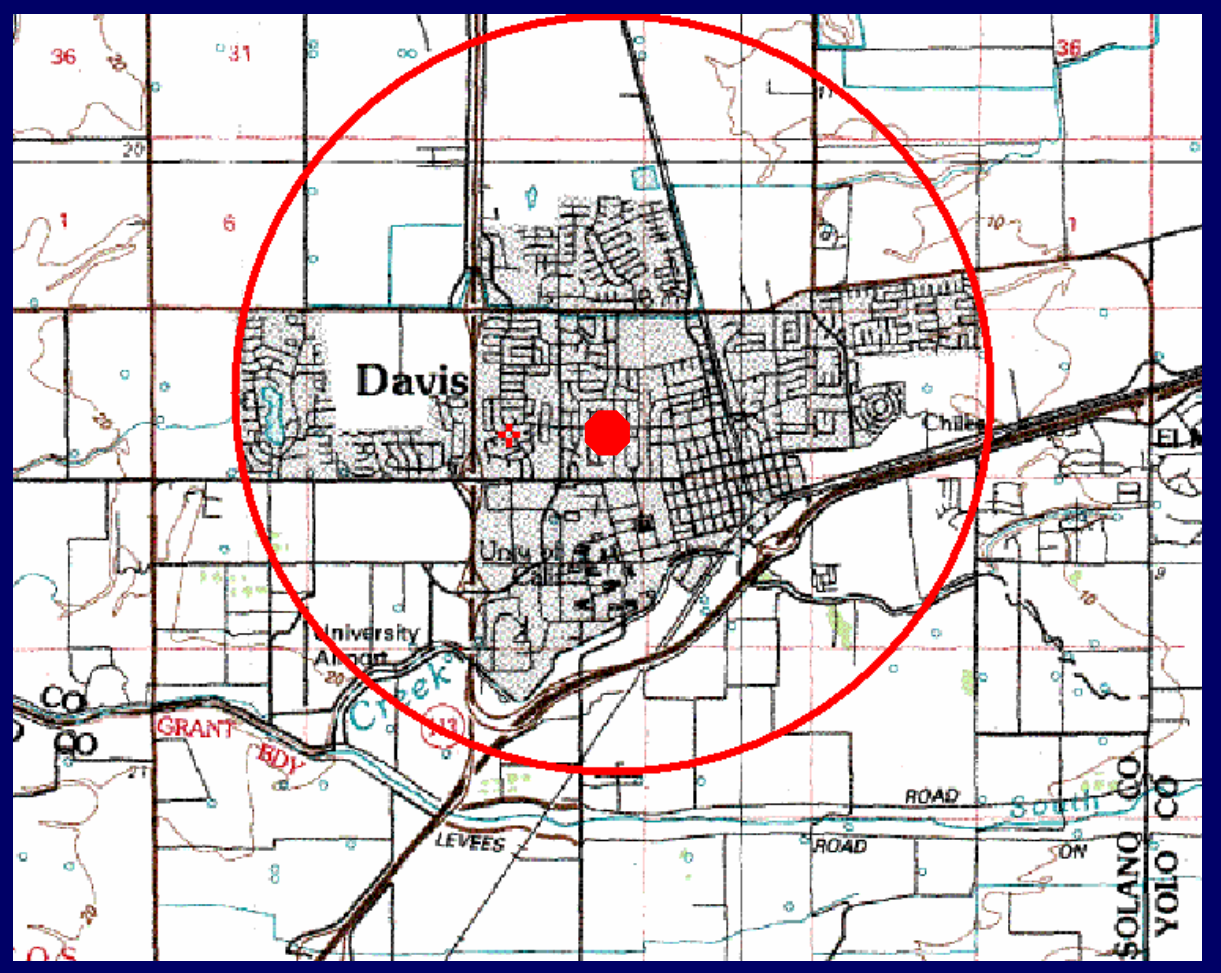

www.manisnet.org 


\section{Environmental Data (raster GIS data layers)}
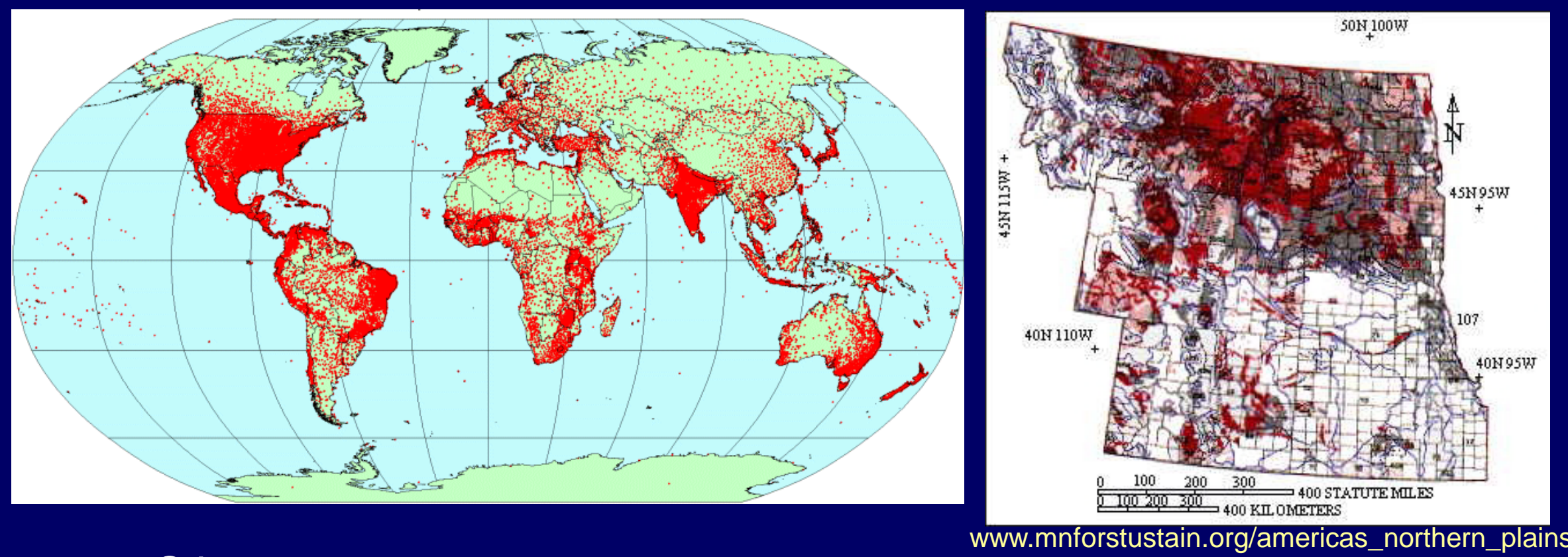

- Climate

$\square$ Weather station data

- Soil characteristics

$\square$ Long temporal applicablity

- Vegetation data

- WorldClim

$\square \quad$ www.worldclim.com
- UNEP GeoData Portal

$\square$ www.geodata.grid.unep.ch/data 


\section{Environmental Data (raster GIS data layers)}

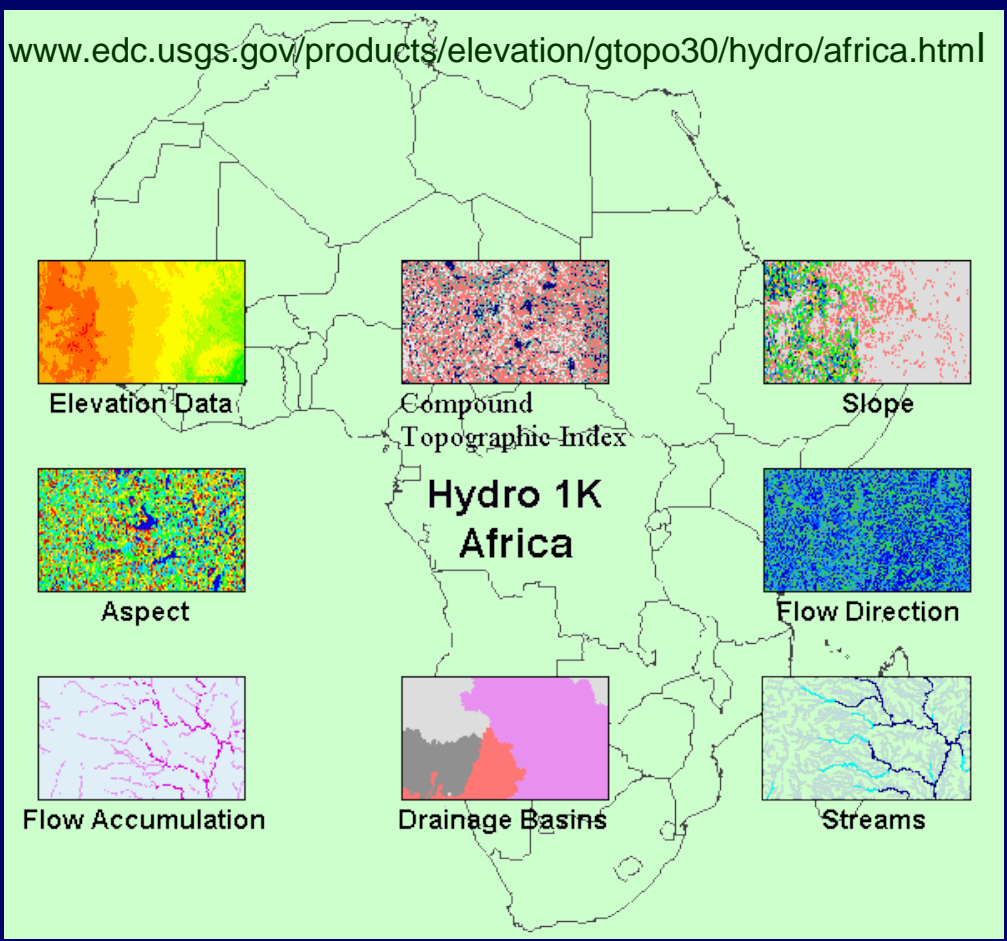

- Topography

- USGS Hydro-1K DEM

$\square$ www.edc.usgs.gov www.resonancepub.com

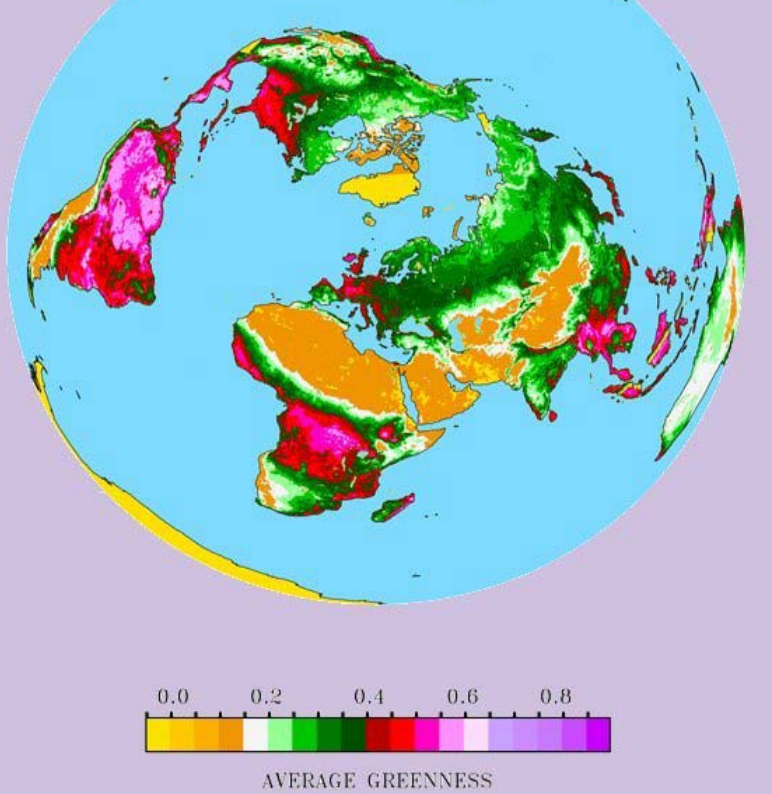

- Normalized Difference Vegetation Index (NDVI)

- University of Maryland

$\square$ AVHRR satellite

$\square$ www.glcf.umiacs.umd.edu 


\section{Environmental Data}

- Environmental Data - 30 total layers

$\square$ Climate - 19 variables

$\square$ Topography - 4 variables

$\square$ Soil \& Vegetation - 5 variables

$\square$ Surface reflectance (monthly NDVI composites) - 12 variables

- Must determine

$\square$ How much data is enough....

$\square$ Which variables are best suited for model construction.... 


\section{Ecological Niche Modeling: Maxent}

www.es.princeton.edu $\sim$ schapire/maxent

- General purpose maximum entropy-based machine learning method

- Origins:

$\square$ Statistical mechanics

$\square$ Bayesian statistics

- Entropy:

$\square$ A measure of the disorder or randomness in a closed system

$\square$ The tendency for all matter and energy to evolve toward a state of disorder 


\section{Ecological Niche Modeling: Maxent}

www.es.princeton.edu schapire/maxent

- Estimates the EN as a probability distribution

$\square$ Closest to maximum entropy

subject to the constraint that higher probabilities

will occur under conditions associated with observed presence

- Performs statistical analysis

$\square$ Environmental variable suitability

- Niche model construction:

$\square$ Presence-only occurrence data

$\square 10,000$ random background points representing non-occurrence

$\square$ Environmental data 


\section{Analysis of Ecological Factors}

- Jackknife Analysis

- N layers ( $N=30$ total \# layers used)

- N-1 layers

$\square$ omitted each variable sequentially

$\square$ assess importance of variables by examining effects of their omission

$\square 2$ analyses

- Suites of environmental variables

- Individual variables 


\section{Environmental Data}

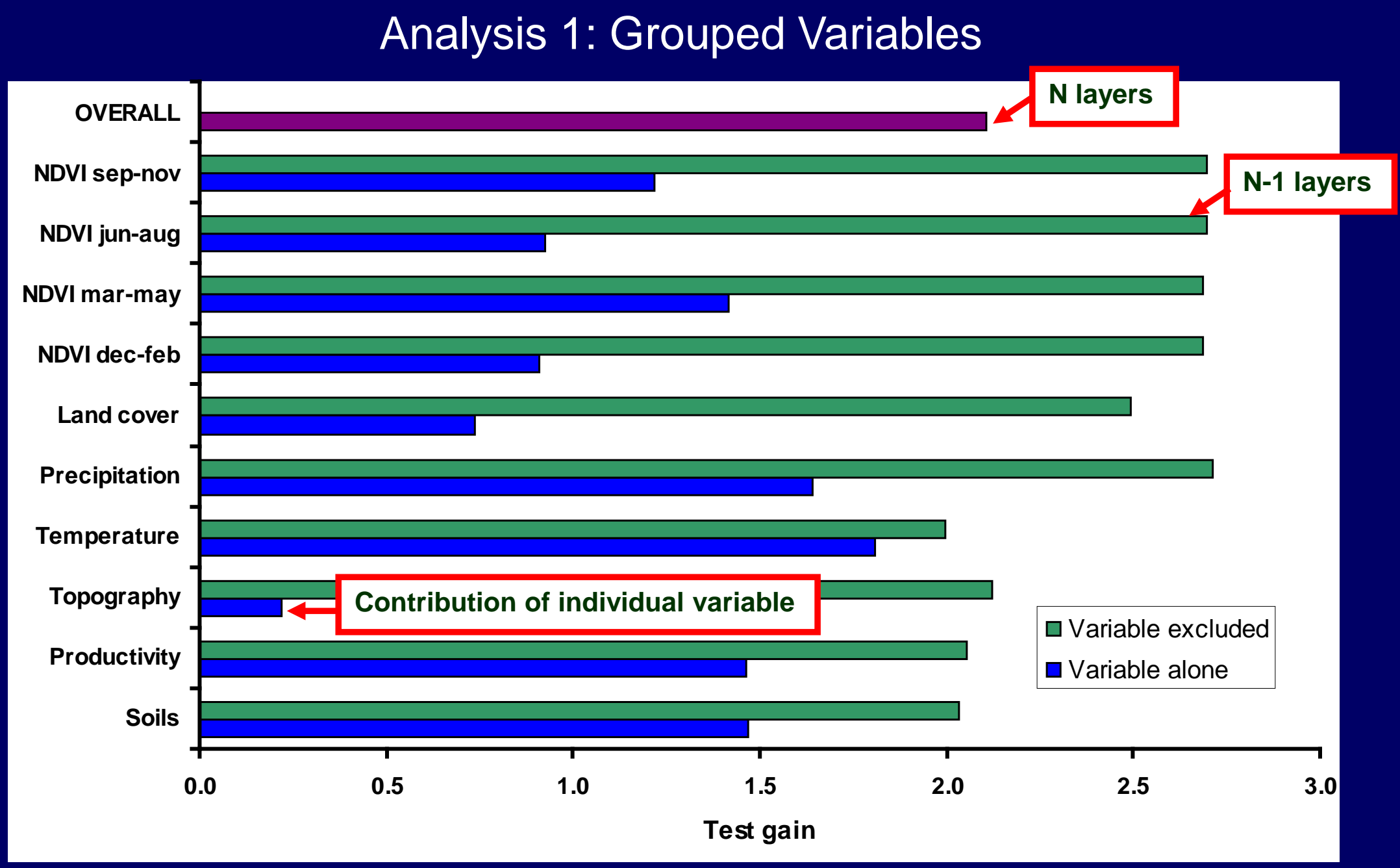




\section{Environmental Data}

\section{Analysis 2: Individual variables}

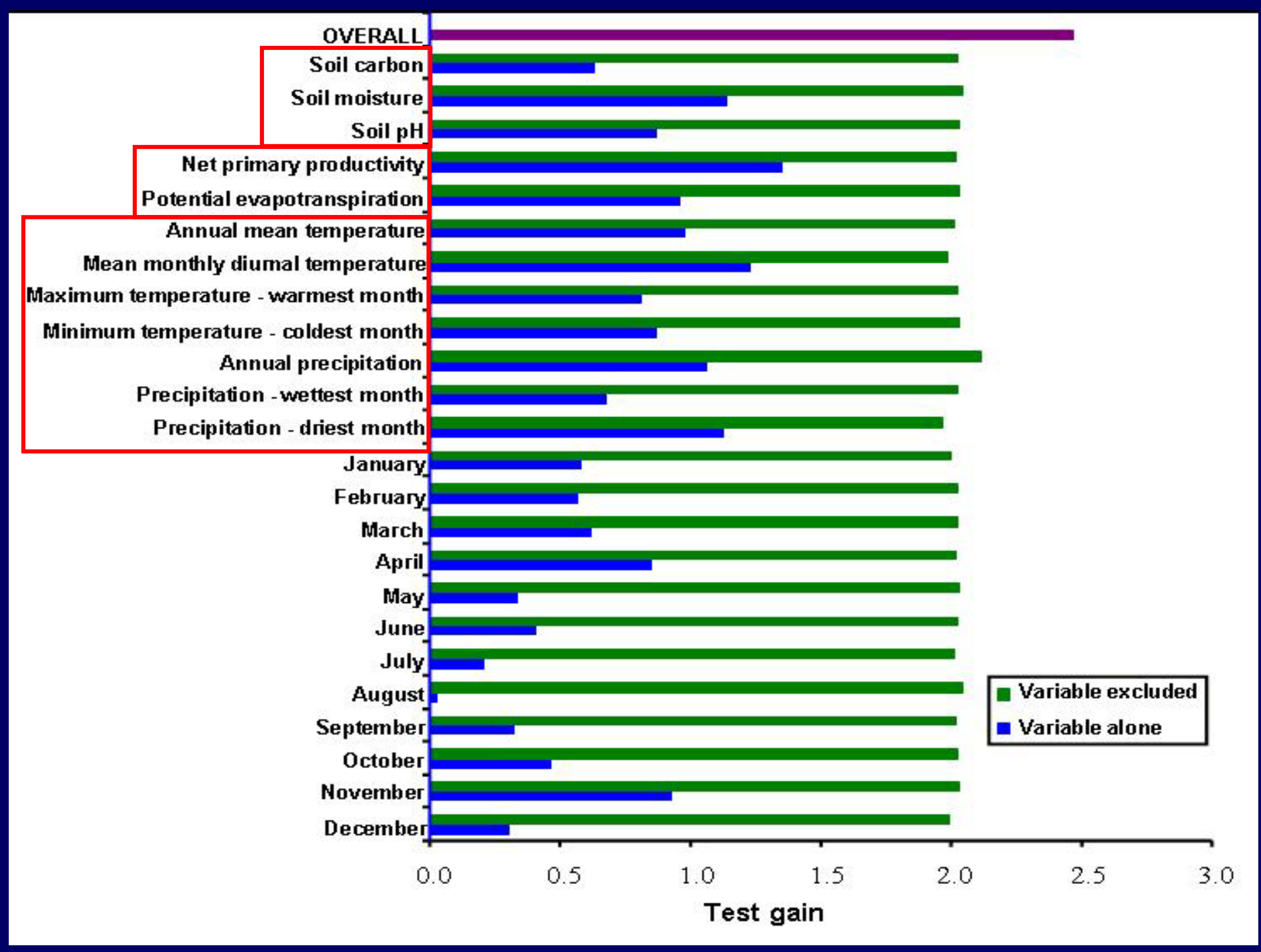




\section{Monkeypox Ecology and Geography}

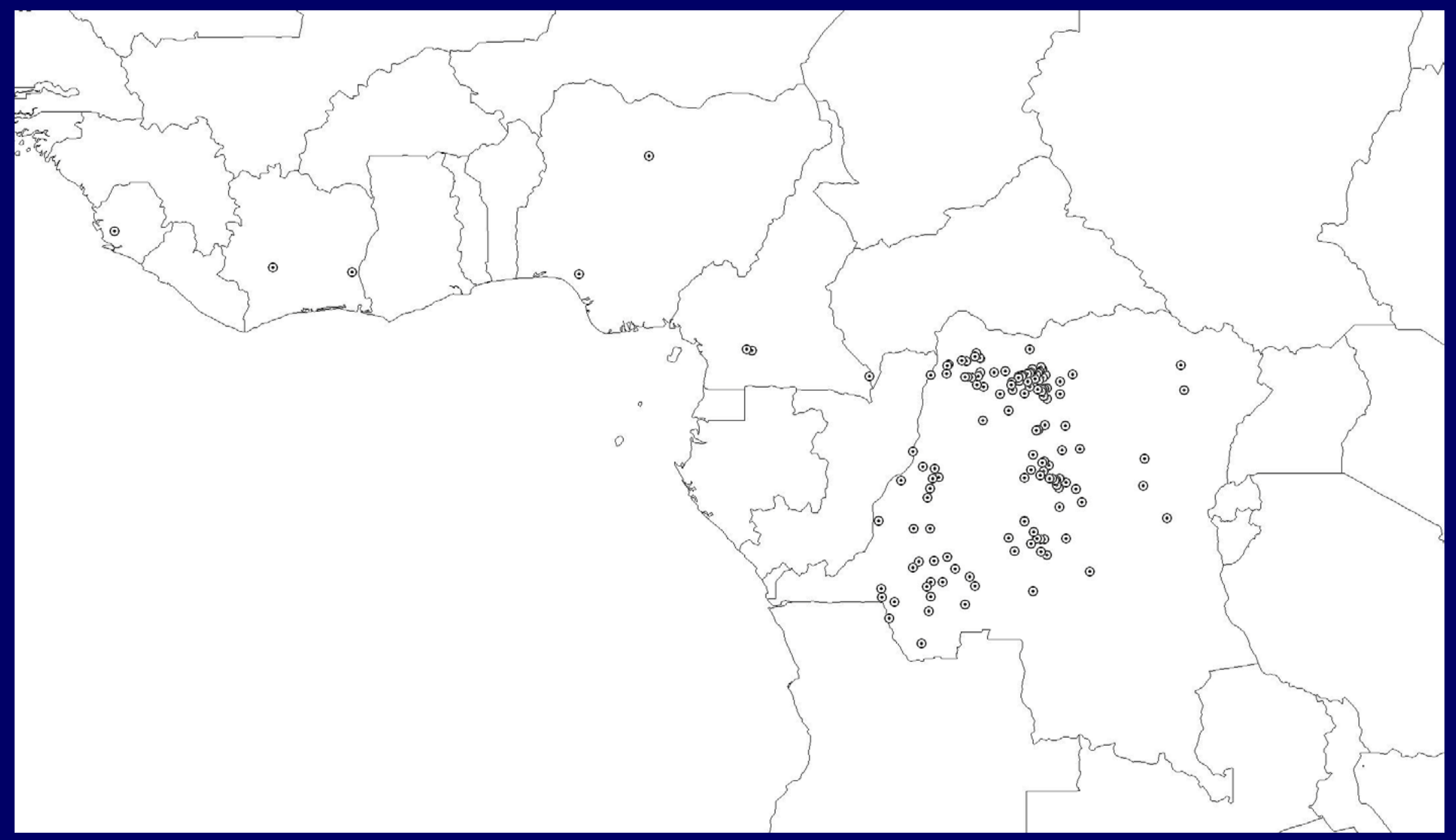




\section{Monkeypox Ecology and Geography}

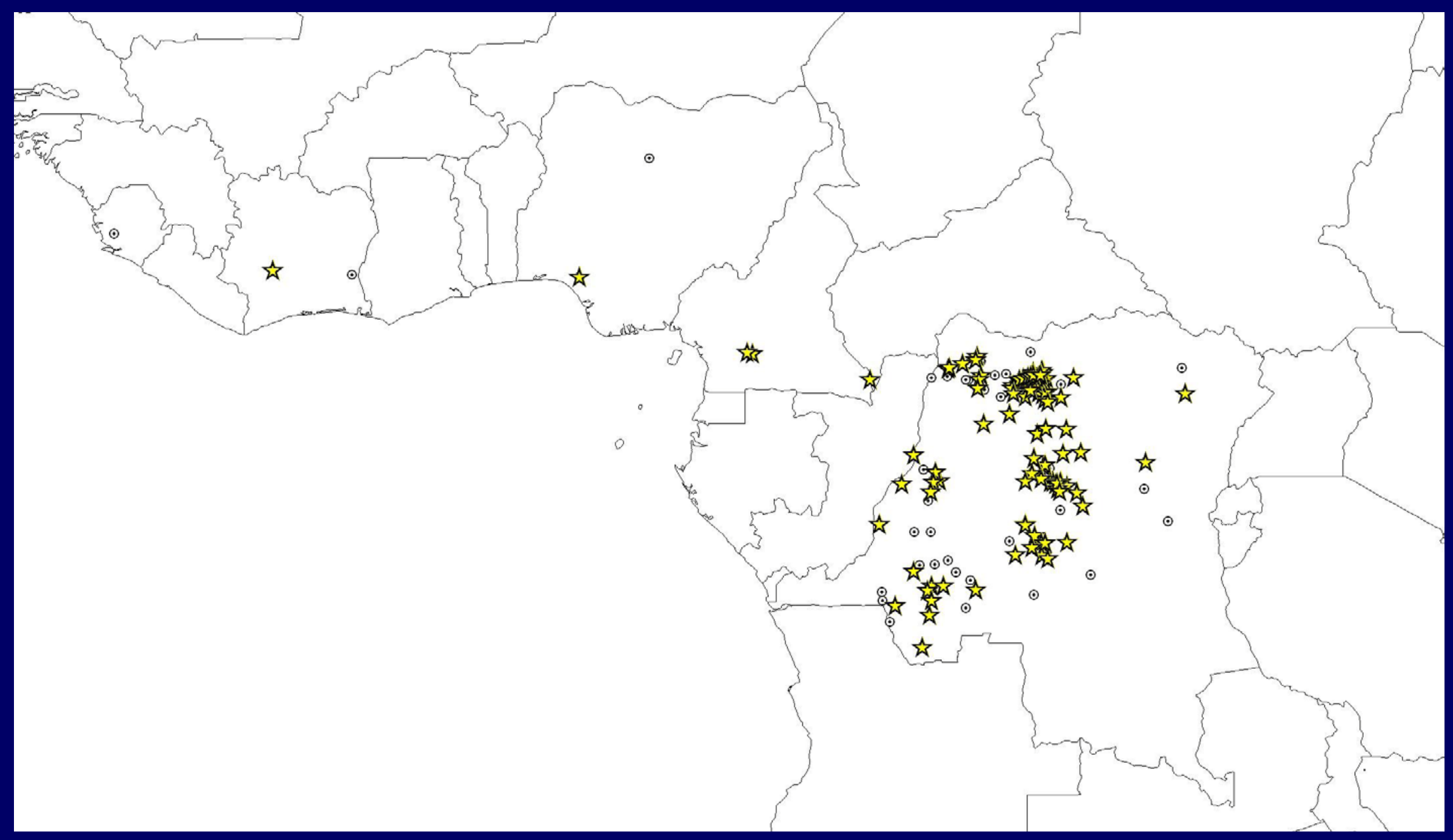




\section{Monkeypox Ecology and Geography}

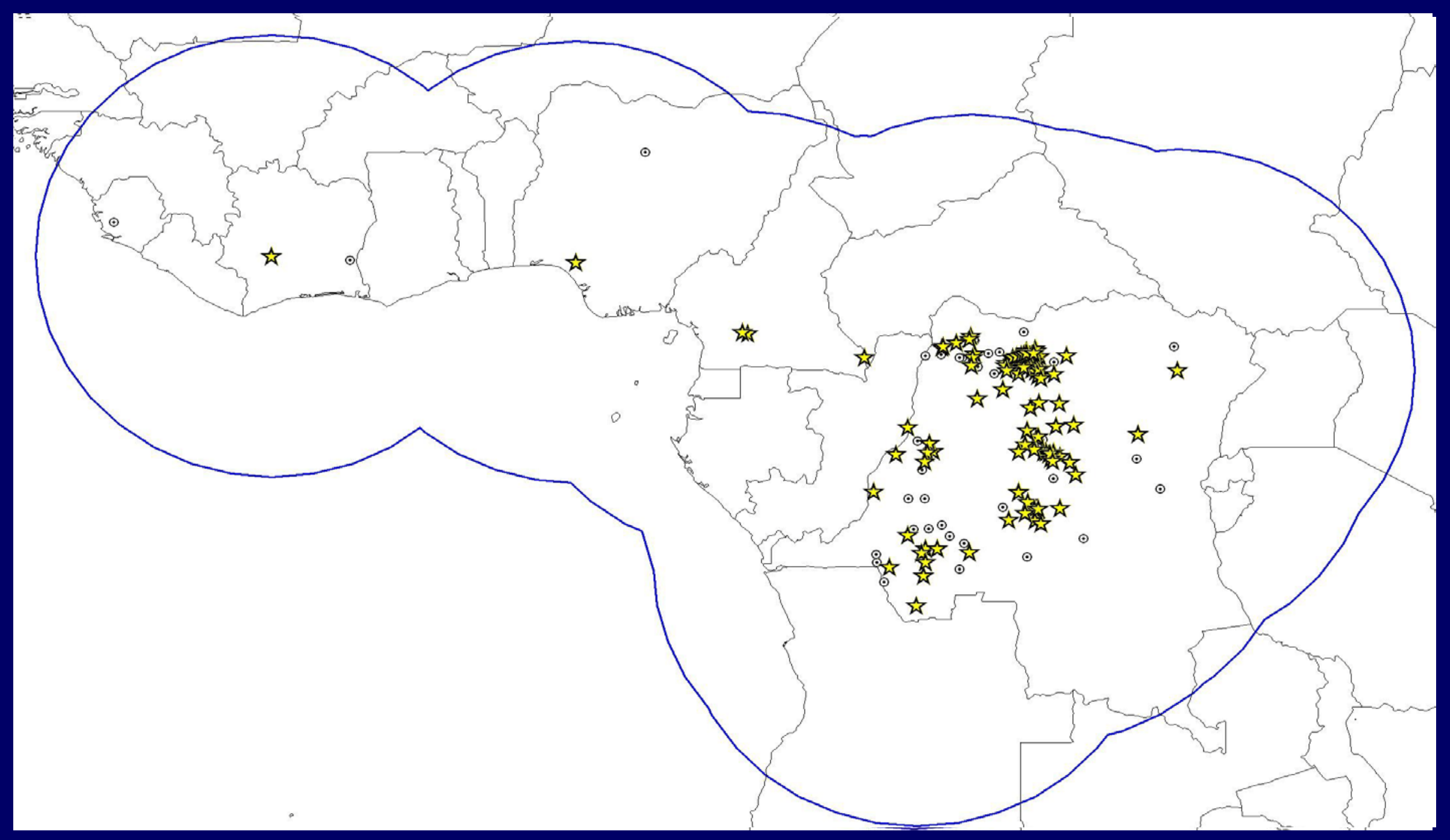




\section{Monkeypox Ecology and Geography}

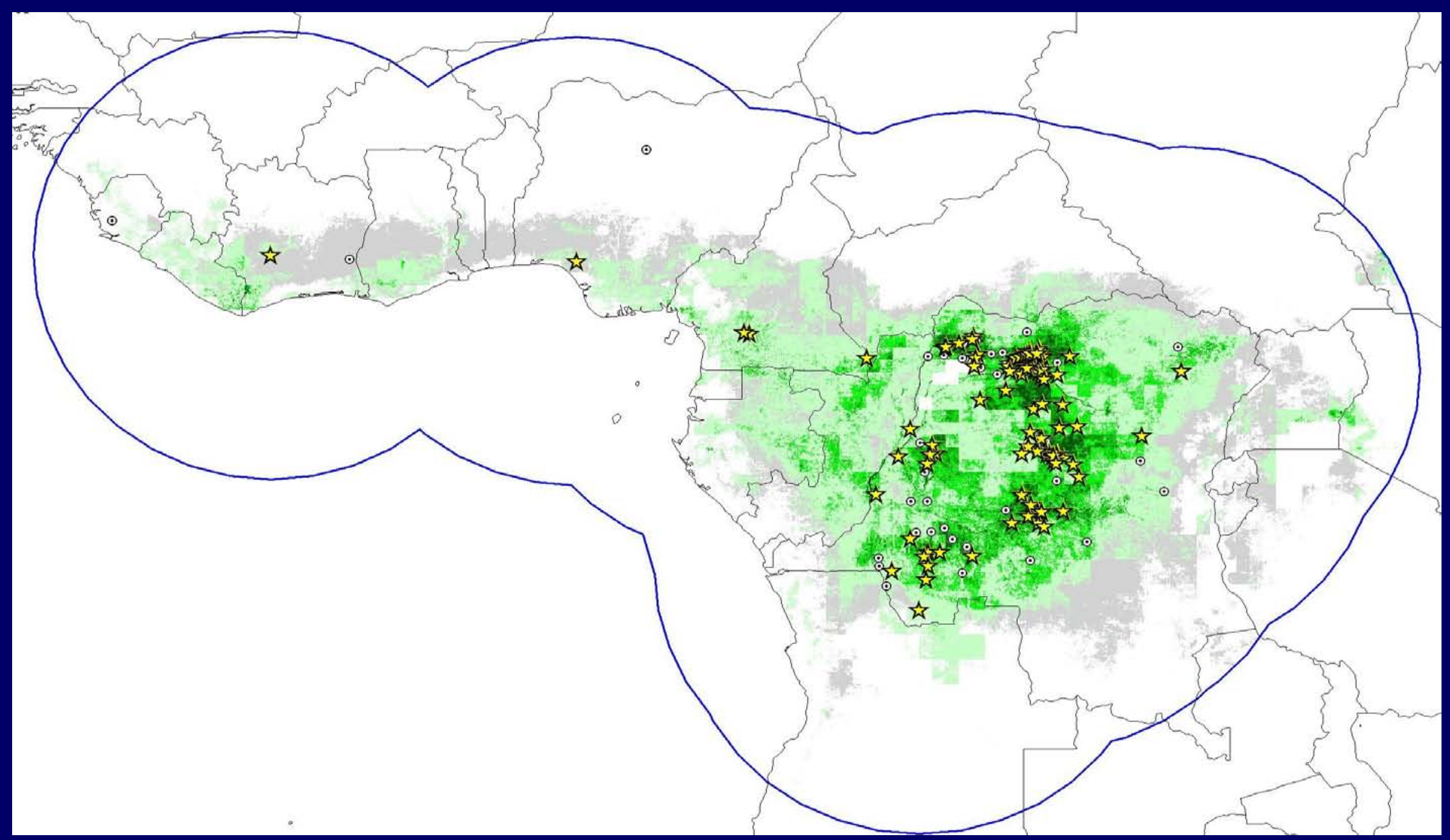




\section{Monkeypox Ecological Niche}

\section{mean annual precipitation vs. mean annual temperature}

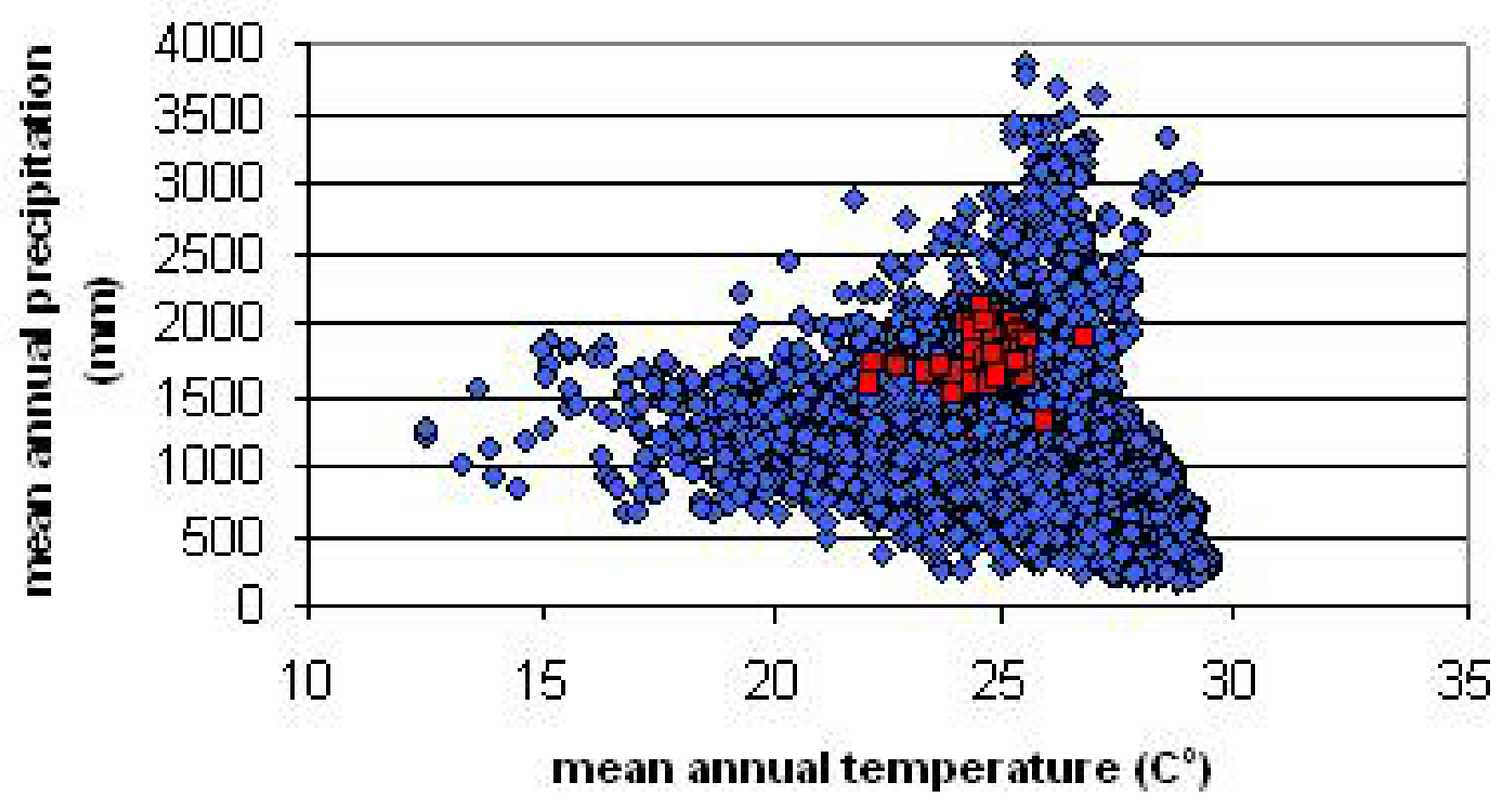

- Available

- Presence

mean annual temperature $\left(C^{\circ}\right)$ 


\section{Monkeypox Ecological Niche}

potentlal evapotraniplration (mm) vi. net primary productivty (Roal/m ${ }^{2}$ yr)

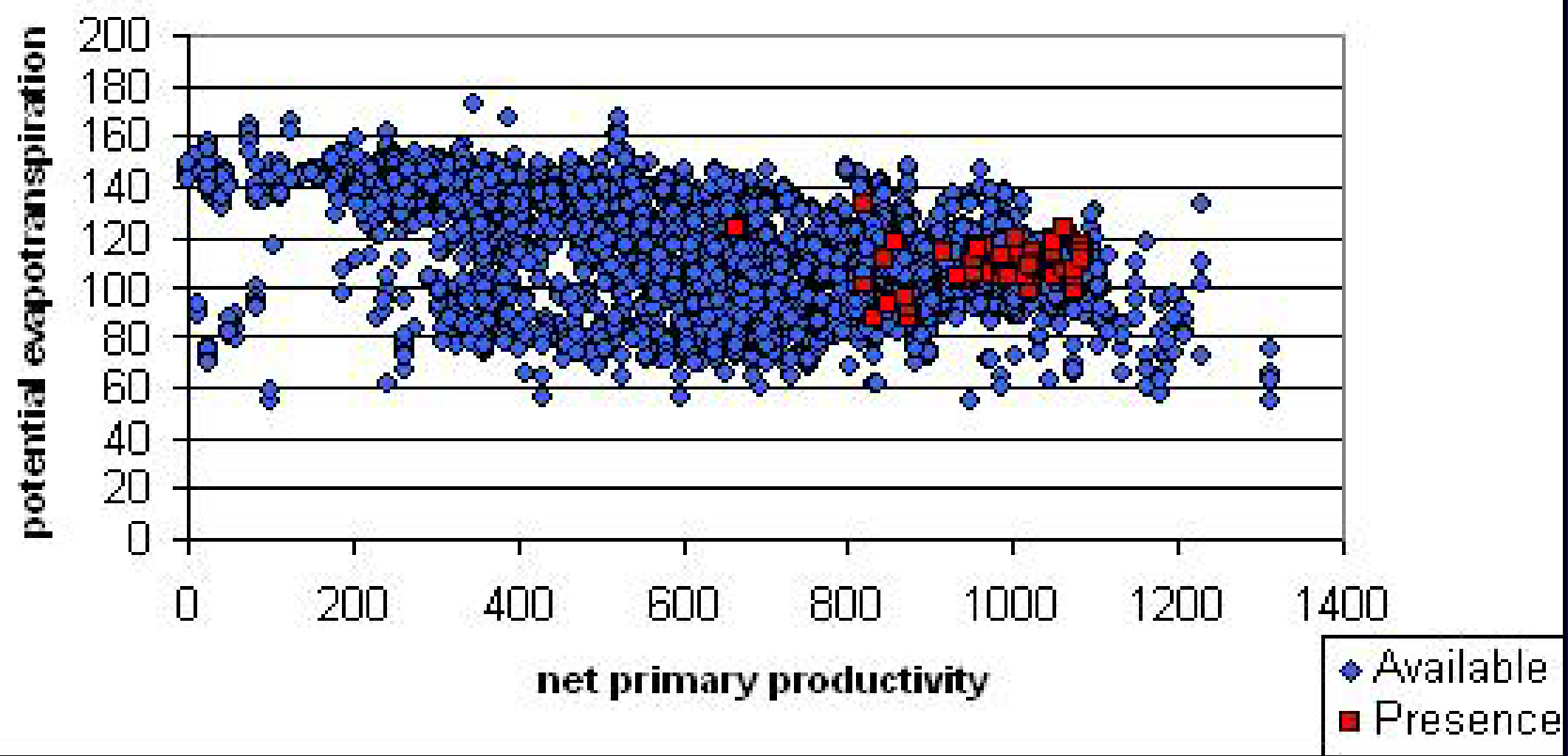




\section{Ecological Niche Variable Ranges}

\begin{tabular}{|l|l|l|}
\hline & $\begin{array}{l}\text { Areas of } \\
\text { Known Occurrence }\end{array}$ & $\begin{array}{l}\text { Areas of Predicted } \\
\text { Favorable Environment }\end{array}$ \\
\hline Mean annual precipitation & $1500-2100 \mathrm{~mm}$ & $500-3500 \mathrm{~mm}$ \\
\hline Precipitation of wettest month & $2000-2500$ & $600-4500 \mathrm{~mm}$ \\
\hline Mean annual temperature & $21-26^{\circ} \mathrm{C}$ & $15-30^{\circ} \mathrm{C}$ \\
\hline $\begin{array}{l}\text { Maximum temperature } \\
\text { warmest month }\end{array}$ & $30-34^{\circ} \mathrm{C}$ & $25-42{ }^{\circ} \mathrm{C}$ \\
\hline Potential evaoptranspiration & $80-120 \mathrm{~mm}$ & $60-160 \mathrm{~mm}$ \\
\hline Net primary productivity & $800-1100 \mathrm{Kcal} / \mathrm{m}^{2} \mathrm{l}$ year & $100-1200 \mathrm{Kcal} / \mathrm{m}^{2} / \mathrm{year}$ \\
\hline Soil pH & $5-6$ & $5-7.5$ \\
\hline Soil carbon & $4-10 \%$ & $1-11 \%$ \\
\hline
\end{tabular}




\section{Characterizing Distributional Limits}

mean annual precipitation ( $\mathrm{mm}$ )

vs.
mean annual temperature $\left({ }^{\circ} \mathrm{C}\right)$

vs.
mean annual temperature $\left({ }^{\circ} \mathrm{C}\right)$

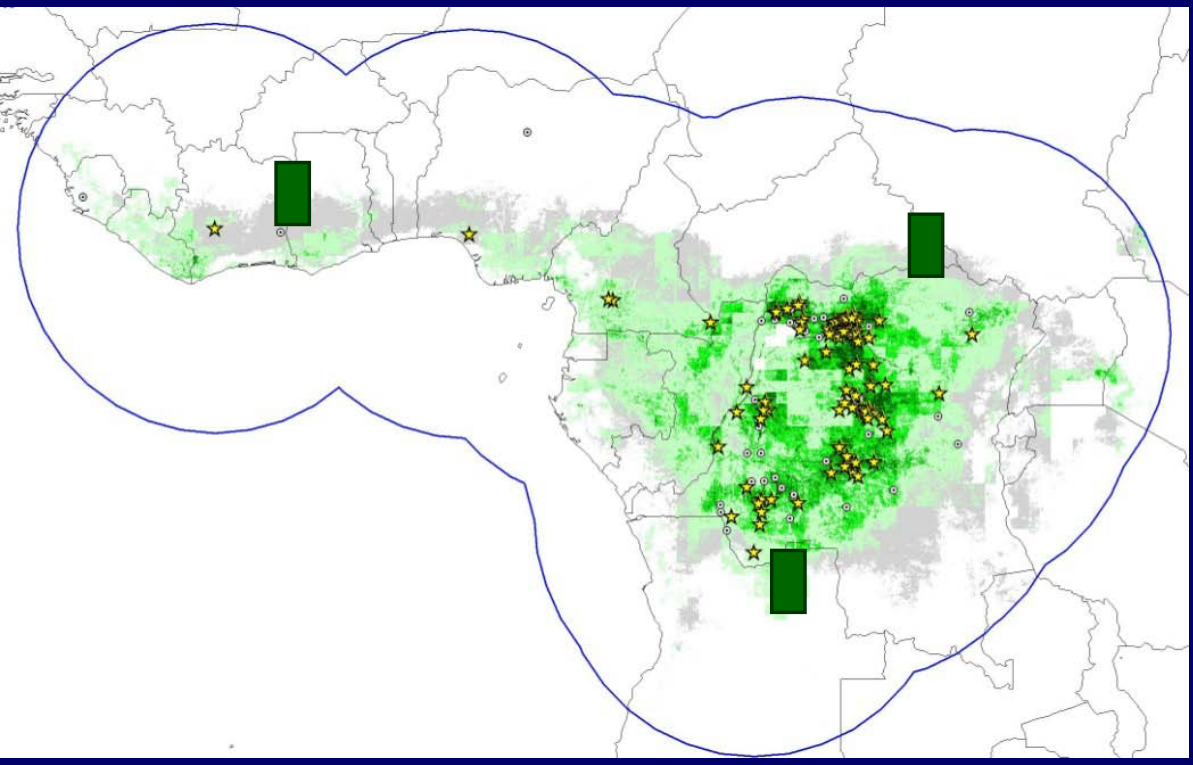




\section{Characterizing Distributional Limits}

November NDVI

vs.

soil moisture (mm)

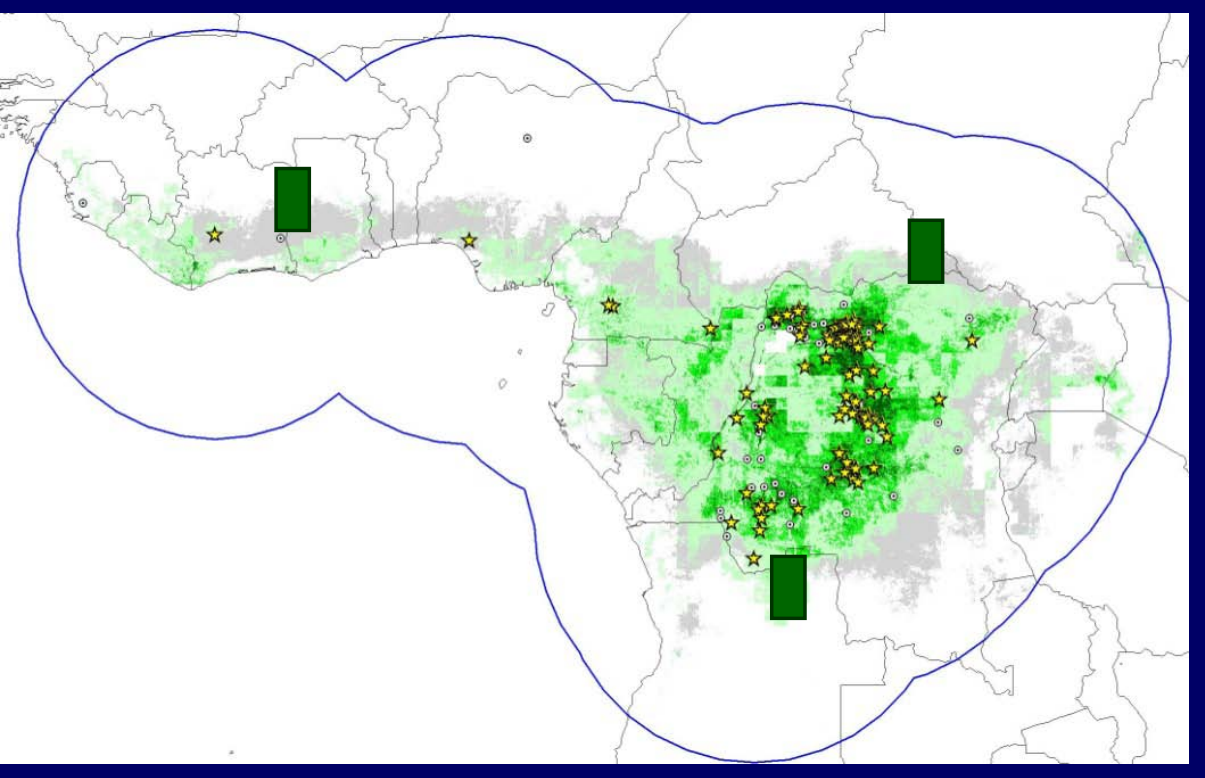

$\left.{ }^{70}\right]$ Northwest 


\section{Monkeypox Ecology and Geography}

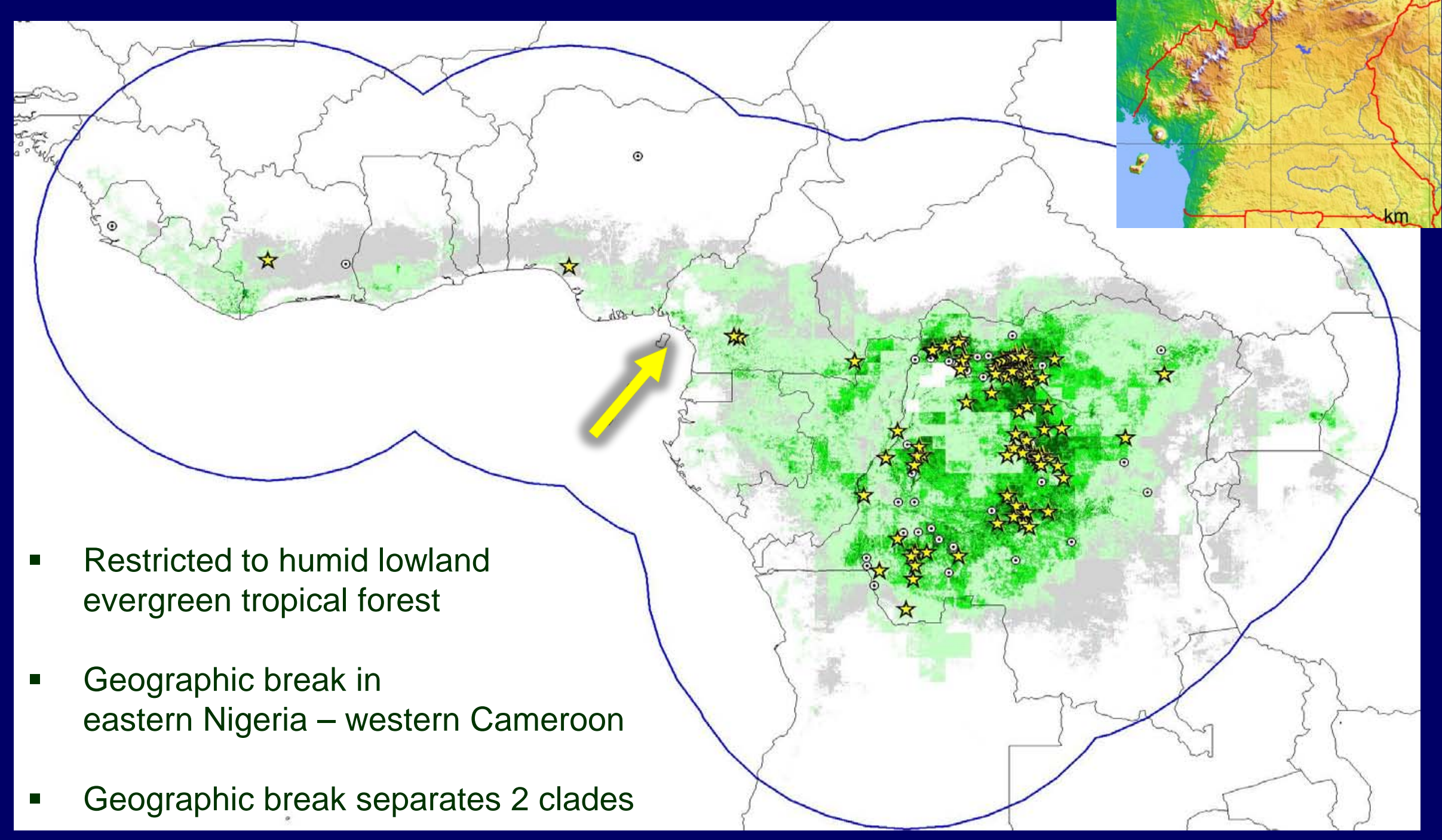




\title{
Comparison with Previous Study
}

\section{Ecological Niche and Geographic Distribution of Human Monkeypox in Africa}

\author{
Rebecca S. Levine ${ }^{1}$, A. Townsend Peterson ${ }^{2}$, Krista L. Yorita ${ }^{3}$, Darin Carroll ${ }^{1}$, Inger K. Damon ${ }^{1}$, Mary G. Reynolds ${ }^{1 *}$
}

1 Centers for Disease Control and Prevention, Poxvirus Program, Atlanta, Georgia, United States of America, 2 Natural History Museum and Biodiversity Research Center, University of Kansas, Lawrence, Kansas, United States of America, $\mathbf{3}$ Centers for Disease Control and Prevention, Division of Viral and Rickettsial Diseases, Atlanta, Georgia, United States of America

Monkeypox virus, a zoonotic member of the genus Orthopoxviridae, can cause a severe, smallpox-like illness in humans. Monkeypox virus is thought to be endemic to forested areas of western and Central Africa. Considerably more is known about human monkeypox disease occurrence than about natural sylvatic cycles of this virus in non-human animal hosts. We use human monkeypox case data from Africa for 1970-2003 in an ecological niche modeling framework to construct predictive models of the ecological requirements and geographic distribution of monkeypox virus across West and Central Africa. Tests of internal predictive ability using different subsets of input data show the model to be highly robust and suggest that the distinct phylogenetic lineages of monkeypox in West Africa and Central Africa occupy similar ecological niches. High mean annual precipitation and low elevations were shown to be highly correlated with human monkeypox disease occurrence. The synthetic picture of the potential geographic distribution of human monkeypox in Africa resulting from this study should support ongoing epidemiologic and ecological studies, as well as help to guide public health intervention strategies to areas at highest risk for human monkeypox.

Citation: Levine RS, Peterson AT, Yorita KL, Carroll D, Damon IK, et al (2007) Ecological Niche and Geographic Distribution of Human Monkeypox in Africa. PLoS ONE 2(1): e176. doi:10.1371/journal.pone.0000176 
This study

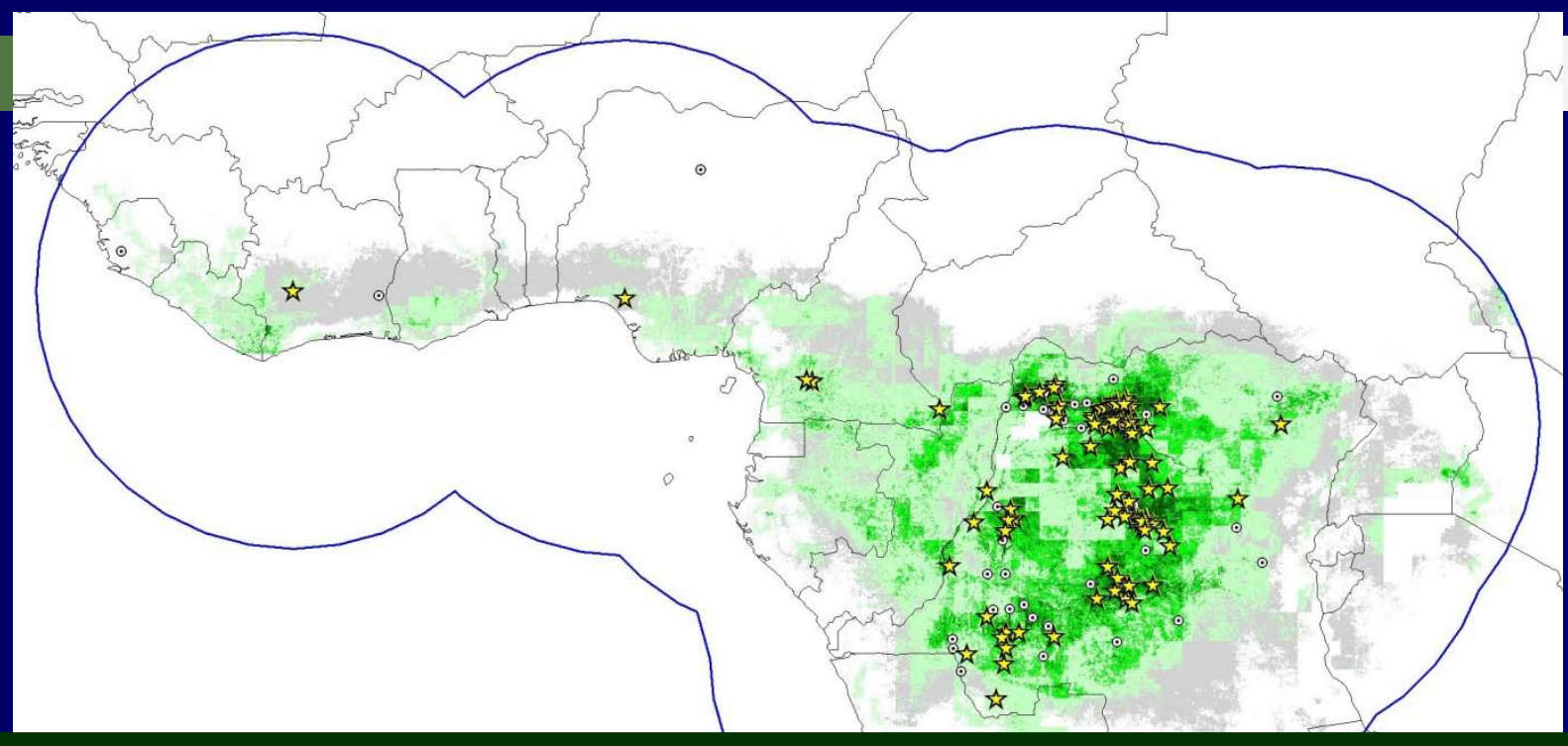

Serologic Evidence for Novel Poxvirus in Endangered Red Colobus Monkeys, Western Uganda Goldberg TL etal

Emerging Infectious Diseases, May 2008, 14(5): 801-803

Levine et al.

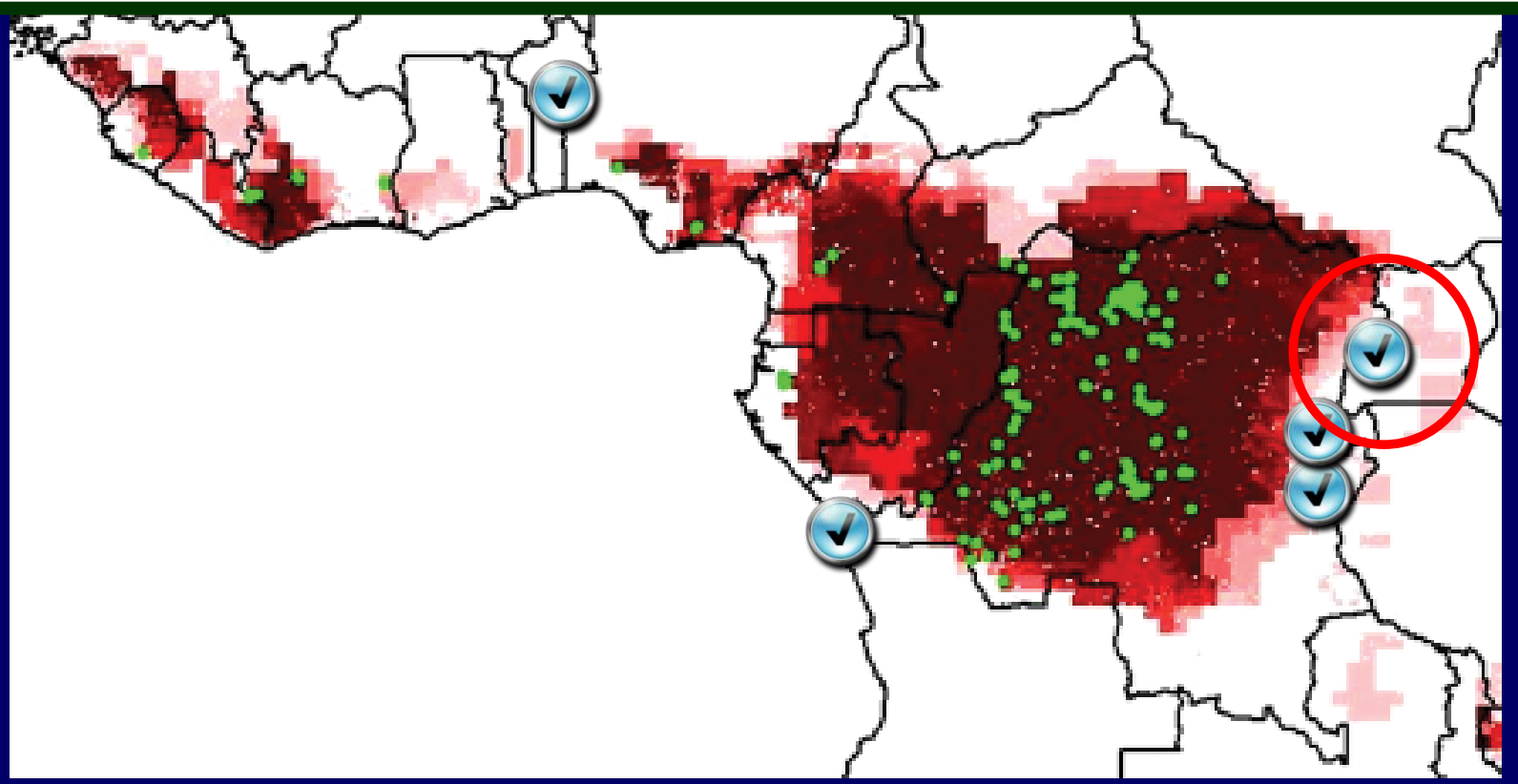




\section{Comparison with Previous Study}

Levine et al.

- Climate, topography, landcover

- 156 occurrences, no error "filter"

- Assessment of variable importance

$\square$ Student's t-test

$\square$ Kappa statistic

\section{This study}

- Climate, soil, vegetation, NDVI

- 139 occurrences, used an error "filter"

- Assessment of variable importance

$\square$ Jackknife 


\section{Summary}

- Niche models are useful in identifying ecological parameters associated with disease occurrence

\begin{tabular}{|l|l|l|}
\hline & $\begin{array}{l}\text { Areas of } \\
\text { Known Occurrence }\end{array}$ & $\begin{array}{l}\text { Areas of Predicted } \\
\text { Favorable Environment }\end{array}$ \\
\hline Mean annual precipitation & $1500-2100 \mathrm{~mm}$ & $500-3500 \mathrm{~mm}$ \\
\hline Precipitation of wettest month & $2000-2500$ & $600-4500 \mathrm{~mm}$ \\
\hline Mean annual temperature & $21-26{ }^{\circ} \mathrm{C}$ & $15-30^{\circ} \mathrm{C}$ \\
\hline $\begin{array}{l}\text { Maximum temperature } \\
\text { warmest month }\end{array}$ & $30-34^{\circ} \mathrm{C}$ & $25-42{ }^{\circ} \mathrm{C}$ \\
\hline Potential evaoptranspiration & $80-120 \mathrm{~mm}$ & $60-160 \mathrm{~mm}$ \\
\hline Net primary productivity & $800-1100 \mathrm{Kcal} / \mathrm{m}^{2} \mathrm{l}$ year & $100-1200 \mathrm{Kcal} / \mathrm{m}^{2} /$ year \\
\hline Soil pH & $5-6$ & $5-7.5$ \\
\hline Soil carbon & $4-10 \%$ & $1-11 \%$ \\
\hline
\end{tabular}




\section{Summary}

- Niche model quality is affected by

$\square$ Georeferencing methodology

- Use of spatial precision filters

$\square$ MaNIS point radius method

$\square$ Quality and types of environmental data

- Data sources

- Statistical analysis 


\section{Summary}

- Niche models have applicable and versatile uses in spatial epidemiology

$\square$ Identify environmental characteristics associated with disease occurrence

$\square$ Identifying Identify components of transmission cycle

$\square$ Identify foci of disease occurrence

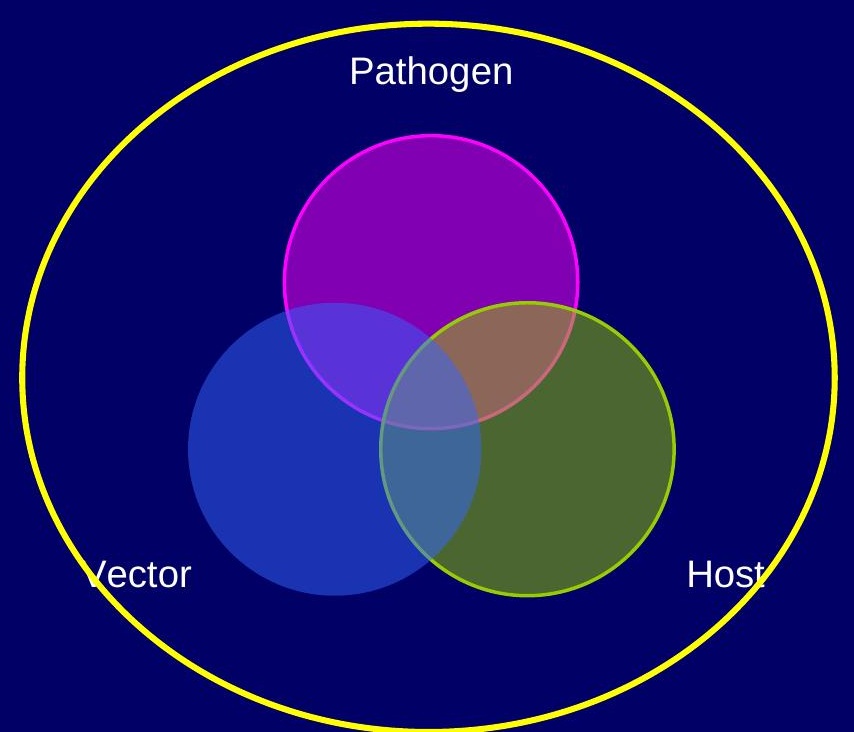




\section{Acknowledgments}

- Coaching:

$\square$ Patricia Payne, advisor

$\square$ A. Townsend Peterson, co-advisor

$\square$ Deon van der Merwe, committee

$\square$ Gail Hansen, committee

\section{KSU:}

M. M Chengappa, employment Walter Dodds, support Giña Scott, IT support

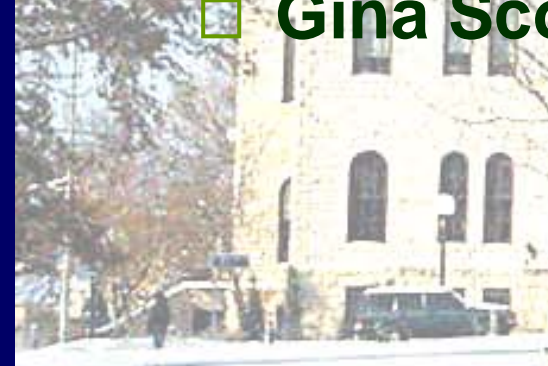

- CDC

$\square$ Darin Carroll

$\square$ Ryan Lash

WHO

悬

$\square$ Pierre Formenty
- KU

Mona Papeş

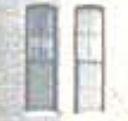

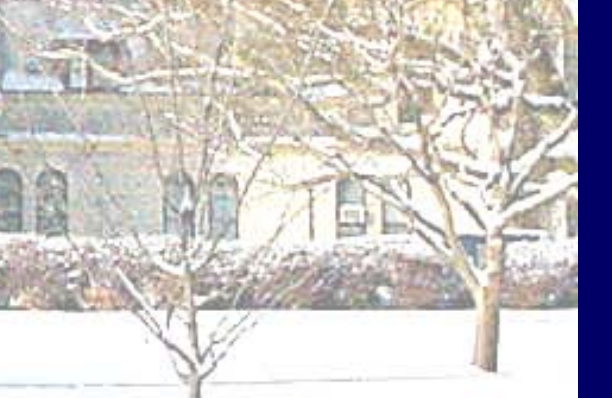


